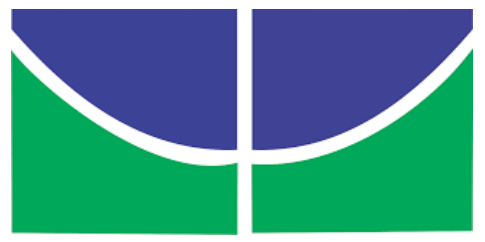

Universidade de Brasília

Instituto de Ciências Biológicas

Departamento de Botânica

\title{
Morfologia e Filogenia de Polytrichastrum alpinum (Hedw.) G.L. Sm., uma Espécie Bipolar
}

\author{
JÚLIA VIEGAS MUNDIM \\ ORIENTADOR: PAULO EDUARDO AGUIAR SARAIVA CÂMARA
}

Brasília-DF

Janeiro, 2016 

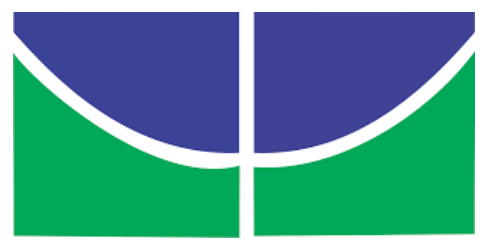

Universidade de Brasília

Instituto de Ciências Biológicas

Departamento de Botânica

\title{
Morfologia e Filogenia de Polytrichastrum alpinum (Hedw.) G.L. Sm., uma Espécie Bipolar
}

\author{
JÚLIA VIEGAS MUNDIM
}

Defesa de mestrado a ser apresentada à Coordenação do Programa de Pós Graduação em Botânica da Universidade de Brasília como parte dos requisitos necessários para obtenção do título de Mestre em Botânica

ORIENTADOR Dr. PAulo EduARdo Aguiar SARAIVA CÂMARA 


\section{AGRADECIMENTOS}

Ao meu querido orientador, Dr. Paulo, que me possibilitou realizar este trabalho, me fornecendo não só orientação, mas sua amizade e apoio nos momentos de necessidade.

Ao Dr. Michael Stech e o Dr. Denilson Peralta pelas contribuições.

A Dra. Micheline pelo acolhimento.

As técnicas Josemília Miranda e Marina pelo auxílio.

Aos amigos do laboratório de criptógamas, Abel, Allan, Amanda, Bárbara, Carla, Diego (Picachu) e Osvanda, sempre amáveis e solícitos.

As amigas Ana Gabriela e Tamara, parceiras de trabalho e companheiras em todos os momentos.

Ao Proantar (Programa Antártico Brasileiro), Marinha do Brasil, Força Aérea Brasileira, MCTI e amigos da marinha pelos apoios logístico e operacional que possibilitaram as coletas.

As agências de financiamento, CAPES e CNPq.

As estações antárticas Arctowski, Ferraz, Júlio Escudero, Frei e Artigas pelo acolhimento durante as coletas.

Aos herbários pelos empréstimos de material.

Aos colaboradores do Projeto Bipolares e aos amigos que ajudaram durante a realização das coletas, em especial, Patrícia, Adam, Ingrid, Daniela, Deni, Sandra e Paulo Roberto.

Aos professores Dr. Alex, Dra. Bethinha, Dr. Cleilton, Dra. Dulce, Dra. Flávia, Dra. Graça, Dra. Maria Cristina e Dra. Renata A., pelo carinho e as contribuições durante meu processo de formação.

Aos membros da banca avaliadora deste trabalho, Dra. Cássia, Dr. Marcelo Simon, Dr. Luciano e Dra. Graça, por sua paciência e colaborações.

Aos amigos Aline Firminio, Amanda Souza, Andrezza, Alexandre, Diogo Pereira, Fernanda Fiúsa, Fernanda Kurscharski, Flívia, Graziela R., Jair, Jéssica Melo, Lira Júnior, Luan, Mayara A., Nara, Natália Bijos, Pollyanna, Raphael Fuhr, Raquel, Rodrigo, Reneida, Sabrina, Samara, Suzi, pelo companheirismo e carinho em todos os momentos.

Aos meus amados pais José e Eleuza, pela dedicação e amor incondicionais.

Aos meus queridos irmãos, meus inspiradores, Júnior e Juliana, pelo carinho, compreensão, força e incentivo.

Aos irmãos de coração Andressa, Elaine, Ambrósio, Ambrósio Júnior e aos sobrinhos Ana Júlia, Isabela, Joaquim, e Juliane pelo apoio e compreensão.

Ao meu querido Dawid pelo cuidado, amor e incentivo.

A Deus por permitir esse momento.

A todos meus sinceros e eternos agradecimentos. 


\section{Índice}

Índice de Figuras...................................................................................................................i

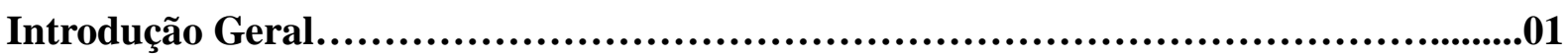

Referências Bibliográficas.........................................................................................04

Capítulo I: Morfologia de Polytrichastrum alpinum (Hedw.) G.L. Sm., uma espécie Bipolar.....................................................................................................................................................06

Resumo..................................................................................................................................07

Abstract.........................................................................................................................07

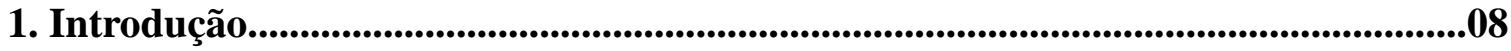

2. Material e Métodos.................................................................................................................10

3. Resultados e Discussão...................................................................................................12

4. Considerações Finais.....................................................................................................20

4. Referências Bibliográficas......................................................................................................21

Capítulo II: Estudos Moleculares de Polytrichastrum alpinum (Hedw.) G.L. Sm., uma Espécie Bipolar Antártica.....................................................................................................................24

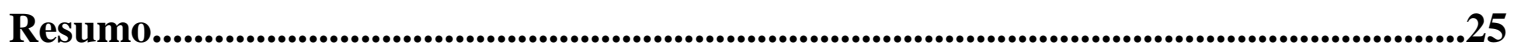

Abstract..................................................................................................................................25

1. Introdução................................................................................................................................26

2. Material e Métodos............................................................................................................28

3. Resultados e Discussão.........................................................................................................31

4. Consideraçø̃es Finais............................................................................................................35

5. Referências Bibliográficas......................................................................................................36

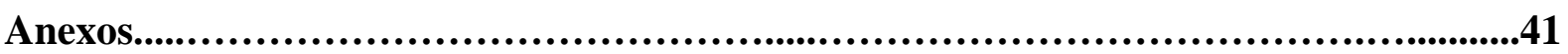




\section{Índice de Figuras}

Capítulo I - Morfologia de Polytrichastrum alpinum (Hedw.) G.L. Sm., uma espécie Bipolar

Figura 1. Polytrichastrum alpinum (Hedw.) G.L. Sm.. A. Corte transversal do filídio. B. C. Gametófito. D. Filídios.

Figura 2. Mapa de distribuição de Polytrichastrum alpinum (Hedw.) G.L. Sm.. Distribuição bipolar. .09

Figura 3. Expedição de campo - Antártica. A. Coleta de material na ASPA 128 ( Antarctic Special Protected Area); B. Secagem de material. . .10

Figura 4. Microscopia Eletrônica de Varredura de Polytrichastrum alpinum G.L. Sm.. proveniente da Antártica. A) Vista abaxial; B) Corte transversal na porção mediana; C) Formato da última fileira de lamelas em corte de secção transversal. .14

Figura 5. Microscopia Eletrônica de Varredura de Polytrichastrum alpinum (Hedw.) G.L. Sm. proveniente do Hemisfério Norte. A) Vista abaxial; B) Corte transversal na porção mediana; C) Formato da última fileira de lamelas em corte de secção transversal................15

Figura 6. Polytrichastrum alpinum. A. Filídio de indivíduo da Antártica. B- C Corte anatômico de filídio para visualização das lamelas, corado com azul de alcião e safranina .16

Figura 7. Polytrichastrum alpinum. A. Filídio de indivíduo do Alasca. B- C Corte anatômico de filídio para visualização das lamelas, corado com azul de alcião e safranina

Figura 8. Corte transversal de caulídio de Polytrichastrum alpinum em indivíduo coletado na Antártica (E) - epiderme; (CE) - Córtex Externo; (CI) - Córtex Interno; (CC) Cilindro Central; (1) - leptóides e (h) - hidroides .18

Figura 9. Corte transversal de caulídio de Polytrichastrum alpinum em indivíduo coletado no Alasca (E) - epiderme; (CE) - Córtex Externo; (CI) - Córtex Interno; (CC) - Cilindro Central; (l) - leptóides e (h)- hidroides. .18

Figura 10. Corte transversal de caulídio de Polytrichastrum alpinum - indivíduo coletado na Antártica. (h) - hidróides e (l) - leptóides.

Figura 11. Corte transversal de caulídio de Polytrichastrum alpinum - indivíduo coletado no Alasca. (h) - hidróides e (l) - leptóides. 
Capítulo II - Análises Moleculares de Polytrichastrum alpinum (Hedw.) G.L. Sm., uma Espécie Bipolar Antártica

Figura 1. Mapa da Distribuição Bipolar de Polytrichastrum alpinum (Hedw.) G.L. $\mathrm{Sm}$ .28

Figura 2. Cladograma de Análise Bayesiana com marcador de cloroplasto trnL-F. Os números apresentados acima dos ramos são, respectivamente, os valores de bootstrap de Máxima Parcimônia e Máxima Verossilhança e probabilidades posteriores da análise Bayesiana. A chave vermelha representa os espécimes de $P$. alpinum unidos no mesmo clado; já a chave azul evidencia a var. septentrionale disposta num clado distinto àquele de P. alpinum. .32

Figura 3. Representação da diversidade haplotípica de Polytrichastrum alpinum através de análise com marcador trnL-F. 


\section{INTRODUÇÃO GERAL}

Durante a Era Paleozóica (Eon Fanerozóico) se formara o supercontinente Pangeia, amalgamação de massas circundada pelo grande oceano Pantalassa. Em virtude de rifteamento, no período Triássico, Pangeia se dividira formando Gonwana e Laurásia (Winge et. al. 2001). Laurásia era formada pelo agrupamento das regiões da América do Norte, Eurásia e Groelândia; separada de Gondwana pelo mar Tethys. Gondwana, por sua vez, se constituía pela junção da África, América do Sul, Austrália e Nova Zelândia, tendo com eixo de junção central, a Antártica. O supercontinente Gondwana esteve posicionado em diferentes regiões, desde a região equatorial até a região polar, na qual teria começado a se dividir (Walton 2013).

A região Antártica, compreendida entre a porção continental e o Oceano Austral, corresponde à extensão de aproximadamente 14 milhões de $\mathrm{km}^{2}$, representando toda região ao sul do paralelo $60^{\circ} \mathrm{S}$ (Brasil 2014).

Ambiente dos superlativos, a Antártica apresenta temperaturas que variam entre $50^{\circ} \mathrm{C}$ (média no platô Antártico - Antártica Oriental) a $-2,8^{\circ} \mathrm{C}$ (média na Estação Antártica Comandante Ferraz); precipitação oscilando entre $1300 \mathrm{~mm}$ anuais nas Ilhas Shetlands do Sul (Antártica Marítima) e $20 \mathrm{~mm}$ por ano na Estação Vostok (continente); e baixa umidade, características bem suportadas por seres extremófilos, capazes de se desenvolver em ambientes com tais especificidades (Longton \& Holdgate 1979, Brasil 2014).

As primeiras expedições exploratórias na Antártica tiveram inicio em meados da década de 1820 por iniciativa das nações americana e britânica. Anotações em diários pessoais das tripulações, advindas da observação casual do ambiente, relatam vagamente a presença de musgos (Ochyra et al. 2008) na região. Young (1821) descreve não ter observado nenhuma vegetação, além de musgos e grama crescendo atrofiadamente.

O primeiro musgo coletado no continente foi um indivíduo do gênero Polytrichastrum (Eights 1837). O material testemunho encontra-se armazenado no herbário do National Museum of Natural History em Washington (US) com duplicata no New York Botanical Garden Herbarium (NY) (Ochyra et al. 2008). A primeira coleção de musgos e líquens do continente foi a Flora Antarctica elaborada por Wilson e Hooker em 1847. A publicação apresenta cinco novas espécies para o continente, número restrito em virtude das condições climáticas do período, que dificultavam o acesso dos barcos e recobriam de neve grande parte da vegetação (Ochyra et al. 2008). Porém a primeira grande coleção de musgos 
antárticos veio apenas em 1898 feita por Emile G. Racovitza, naturalista da expedição belga, (Ochyra et al. 2008).

Logo após a $1^{\text {a }}$ Grande Guerra Mundial, agregou-se maior enfoque cientifico as expedições antárticas, embora inicialmente a botânica estivesse em segundo plano (Ochyra et al. 2008).

Segundo Ochyra et al. (2008), em 1930, pesquisadores norte americanos identificaram várias novas ocorrências de musgos no continente e, até 1961, já haviam sido relatadas 83 espécies, das quais 40 consideradas novas ocorrências em território antártico.

Apesar disso, o reconhecimento da relevância e da representatividade da brioflora antártica, como mais importante componente vegetal local, foi afirmado apenas na ECO-92, no Rio de Janeiro, após um grande período de depressão na taxonomia criptogâmica (Ochyra et al. 2008).

Recentemente, Ochyra et al. (2008), produziu o livro - The Illustrated Moss Flora of Antarctica - publicação que abrange as espécies atualmente conhecidas na flora briológica do continente Antártico, disponibilizando uma gama de informações como descrição e distribuição dos espécimes.

Apesar da inospitalidade, que desfavorece a presença de muitos organismos, principalmente plantas, o continente Antártico possui uma flora criptogâmica significativa. Os espécimes vegetais lá ocorrentes dividem-se, geograficamente, em - Endêmicos da Antártica, Subantárticos, Sul temperado, Bipolar, Cosmopolita e Tropicais (Øvstedal \& Lewis Smith 2001, Ochyra et al. 2008). Predominantemente criptogâmica, a flora é composta por mais de 110 espécies de musgos, sendo 11 espécies endêmicas; aproximadamente 500 espécies de líquens (fungos liquenizados), com cerca de128 espécies endêmicas (Ochyra et al. 2008, Øvstedal \& Lewis Smith 2001, Spielmann \& Pereira 2012); 50 musgos bipolares e 148 líquens bipolares (Ochyra et al. 2008). Espécies bipolares são aquelas compostas por indivíduos semelhantes morfologicamente e que estão distribuídos em ambas às regiões polares (Ártico e Antártico), podendo ou não apresentar ocorrências intermediárias (Ochyra et al. 2008).

As espécies de musgos bipolares correspondem a $45,1 \%$ da diversidade total de musgos antárticos, podendo estas, subdividir-se em bipolar estrito (BI-S) quando ocorrente somente nas regiões polares árticas e antárticas ou bipolar intermediário (BI-I), presente também em outras regiões, como nas tropicais elevadas (Ochyra et al. 2008).

Apesar do isolamento geográfico gerado pela deriva continental, as espécies 
bipolares teriam sua distribuição justificada pela origem holoártica, na qual esses indivíduos teriam chegado às regiões austrais através de dispersão a longa distância (DLD), passando pelas cadeias de montanhas tropicais, sem influência da deriva continental (Dodge 1973, Lamb 1970, Lindsay 1977, Ochyra et al. 2008).

Exceto os trabalhos florísticos (Ochyra et al. 1998, Putzke \& Pereira 2001, Ochyra et al. 2008), existem poucos estudos sobre a diversidade genética que envolvam as espécies e seus respectivos correspondentes polares. Dentre eles, destacam-se aqueles realizados com as espécies Campylopus pyriformis (Schultz) Brid. (Stech \& Wagner 2005, Stech et al. 2010).; Sanionia georgicouncinata (Müll. Hal.) Ochyra \& Hedenäs (Hedenäs 2012).; Leptobryum wilsonii (Mitt.) Broth. Kato et al. (2013); e Bryum argentum Hedw. Pisa et al.(2014); Os dois primeiros, relacionados a bipolaridade, nos quais as espécies eram ditas BI-I, mas após a filogenia receberam novas designações de ampla distribuição.

Dentre as espécies consideradas bipolares intermediárias está Polytrichastrum alpinum (Hedw.) G.L. Sm., primeiro musgo coletado em solo antártico. Alguns dos estudos moleculares mais recentes realizados com Polytrichaceae mostram que o gênero Polytrichastrum é polifilético (Bell e Hyvönen 2010 a, b), e segundo Hyvönen (2010 a) Polytrichastrum alpinum é monofilético.

O objetivo do trabalho foi compreender através de ferramentas moleculares e morfológicas se espécimes de Polytrichastrum alpinum, ocorrentes nas regiões polares e regiões intermediarias são de fato a mesma espécie e, portanto confirmar ou não a sua bipolaridade. 


\section{Referências Bibliográficas}

Bell, Neil E. \& Hyvönen, J. 2010a. Phylogeny of the moss class Polytrichopsida (BRYOPHYTA): Generic-level structure and incongruent gene trees. Molecular Phylogenetics and Evolution. Disponível em: <www.elsevier.com/locate/ympev>.

. 2010b. A phylogenetic circumscription of Polytrichastrum (Polytrichaceae):

Reassessment of sporophyte morphology supports molecular phylogeny. American Journal of Botany 97 (4): 566-7.

Brasil. 2014. Marinha do Brasil. s.d.. Comissão Interministerial para os Recursos do Mar. Proantar. Disponível em: <https://www.mar.mil.br/secirm/proantar.html〉.

Dodge, C.W. 1973. Lichen flora of the Antarctic Continent and adjacent islands. Canaan, New Hampshire: Phoenix publishing. 399 p.

Eights ,J. 1833. Description of a new crustaceous animal found on the shores of the South Shetland Islands, whith remaks on their natural history. Transactions of the Albany Institute. 2: 53-69.

Hedenäs, L. 2012. Global phylogeography in Sanionia uncinata (Amblystegiaceae: Bryophyta). Botanical Journal of the Linnean Society 168: 19-42.

Lamb, I.M. 1970. Antarctic terretrial plants and their ecology.In Antarctic Ecology, 2, ed. M.W. Holdgate, pp. 733-751. London, Academic Press.

Lindsay, D.C. 1977: Lichens of cold deserts. In: Seaward, M.R.D. (Ed.). Lichen Ecology. p. 183-209. London. Academic Press.

Longton, R. E. \& Holdgate, M. W.. 1979. The South Sandwich Islands: 4. Botany. Brit. Antarct. Surv. Sci.. Cambridge University Press.

Ochyra, R. 1998. The moss flora of King George Island, Antarctica. Cracow: Polish Academy 
of Sciences, W. Szafer Institute of Botany.

, R., Lewis Smith, R.I. \& Bednarek-Ochyra H. 2008.The illustrated moss flora of Antarctica. Cambridge: Cambridge University Press.

Øvstedal, D.O. \& Lewis Smith, R.I. 2001. Lichens of Antarcticaand South Georgia: A guide to their Identification and Ecology. Cambridge: Cambridge University Press. 411 p.

Putzke, J. \& Pereira, A.B. 2001. The Antarctic mosses, with special reference to the South Shetland Islands. ULBRA (Universidade Luterana do Brasil), Canoas/RS. 196 pp.

Spielmann, A.A. \& Pereira, A.B. 2012. Lichens on the Maritime Antarctica (a small field guide to some common species).Glalia 4 (3): 01-28.

Stech, M. \& Wagner D. 2005. Molecular relationships, biogeography, and evolution of Gondwanan Campylopus species (Dicranaceae, Bryopsida). Taxon 54: 377-382.

M., Sim-Sim, M. \& Kruijer, J.D. 2010. Campylopus Brid. (Leucobryaceae) in Macaronesia revisited. Trop. Bryol. 31: 154-163.

Young, A. 1821: Notice of the voyage of Edward Barnsfield [sie!]. master of His Majesty's ship Andromache to New South Shetland. Edinburgh Philosophical Journal, 3:345348.

Walton, D. W. H. 2013.Antarctica - Global Science from a Frozen Continent. Cambridge University Press.

Winge, M. 2001. Glossário Geológico Ilustrado. Disponível na em: $<$ http://sigep.cprm.gov.br/glossario/>. 


\section{CAPítulo I}

Morfologia de Polytrichastrum alpinum (Hedw.)

G.L. Sm., uma espécie Bipolar 


\title{
Morfologia de Polytrichastrum alpinum (Hedw.) G.L. Sm., uma espécie Bipolar
}

\author{
Júlia Viegas Mundim ${ }^{1}$ e Paulo Eduardo Saraiva Câmara Aguiar ${ }^{1}$ \\ ${ }^{1}$ Universidade de Brasília, Instituto de Ciências Biológicas, Departamento de Botânica
}

\section{Resumo}

O gênero Polytrichastrum (Polytrichaceae) está distribuído em ambos hemisférios e é composto por quatorze espécies, dentre elas Polytrichastrum alpinum (Hedw.) G.L. Esta planta apresenta gametófito robusto, podendo ser simples ou ligeiramente ramificado e na região do limbo do filídeo são encontradas lamelas, estas taxonomicamente importantes para a identificação da espécie e diferenciação das demais plantas do gênero e da família. Segundo a literatura, esta espécie possui distribuição bipolar intermediária, ocorrendo nas regiões polares e em regiões tropicais de altas altitudes. O objetivo deste estudo foi investigar com mais profundidade a morfologia de espécimes de $P$. alpinum oriundos dos hemisférios Norte e Sul, a fim de verificar o status de bipolaridade proposto. Para isso foram utilizadas ferramentas morfológicas: Microscopia Eletrônica de Varredura (MEV) e anatomia, além de observados os caracteres taxonômicos que definem esta espécie. Através das ferramentas morfológicas citadas foram comparadas amostras advindas de ambas regiões polares e foram encontradas pequenas diferenças morfológicas entre os espécimes que ocorrem na Antártica quando comparados aos do hemisfério Norte. No entanto, estas diferenças podem ocorrer por serem ambientes diferentes e estas podem ser adaptações desta planta às condições extremas que são encontradas na Antártica.

Palavras chave: Antártica, anatomia, bipolaridade, MEV.

\begin{abstract}
The genus Polytrichastrum (Polytrichaceae) is distributed in both hemispheres and consists of fourteen species, among them Polytrichastrum alpinum (Hedw.) GL. This plant has robust gametophyte and can be simple or slightly branched and lamellae are found in leaf limb region, these taxonomically important for species identification and differentiation from other
\end{abstract}


plants of the genus and family. According to the literature, this species have intermediate bipolar distribution, occurring in the polar regions and in tropical regions of high altitudes. The objective of this study was to investigate in more depth the morphology of $P$. alpinum specimens coming from the northern and southern hemispheres, in order to check the status of proposed bipolarity. We used morphological tools: scanning electron microscopy (SEM) and anatomy, as well as observing the taxonomic characters that define this species. Through the aforementioned morphological tools samples were compared arising from both polar regions and found minor morphological differences between species that occur in Antarctica when compared to the Northern Hemisphere. However, these differences can occur are different environments and they may be adapted to the extreme conditions of the plant that are found in Antarctica.

Key words: Antarctica, anatomy, bipolarity, SEM.

\section{Introdução}

Dentre as famílias de musgos acrocárpicos, encontra-se Polytrichaceae (Buck \& Gofinet 2000), composta por 23 gêneros, dentre eles Polytrichastrum, gênero que abarca quatorze espécies, distribuídas entre ambos os hemisférios (Buck \& Gofinet 2000).

O gênero Polytrichastrum foi criado com o intuito de sanar a nomenclatura da espécie Polytrichastrum alpinum (Hedw.) G.L. Sm., que era originalmente descrita como Polytrichum alpinum Hedw., na obra "Species Muscorum Frondosorum 92”, publicada em 1801; sendo posteriormente combinada como Pogonatum alpinum(Hedw.) Röhl., e finalmente classificada como planta do gênero Polytrichastrum, por Smith (1971).

Polytrichastrum alpinum (Figura 1), apresenta gametófito robusto - simples ou ligeiramente ramificado; os filídios possuem formato que varia do ovado ao obovado com margens serrilhadas na porção do limbo e costa única; no limbo, encontram-se as lamelas, característica taxonômica relevante para a diferenciação desta em relação às demais do gênero e da família (Ochyra et al. 2008). 


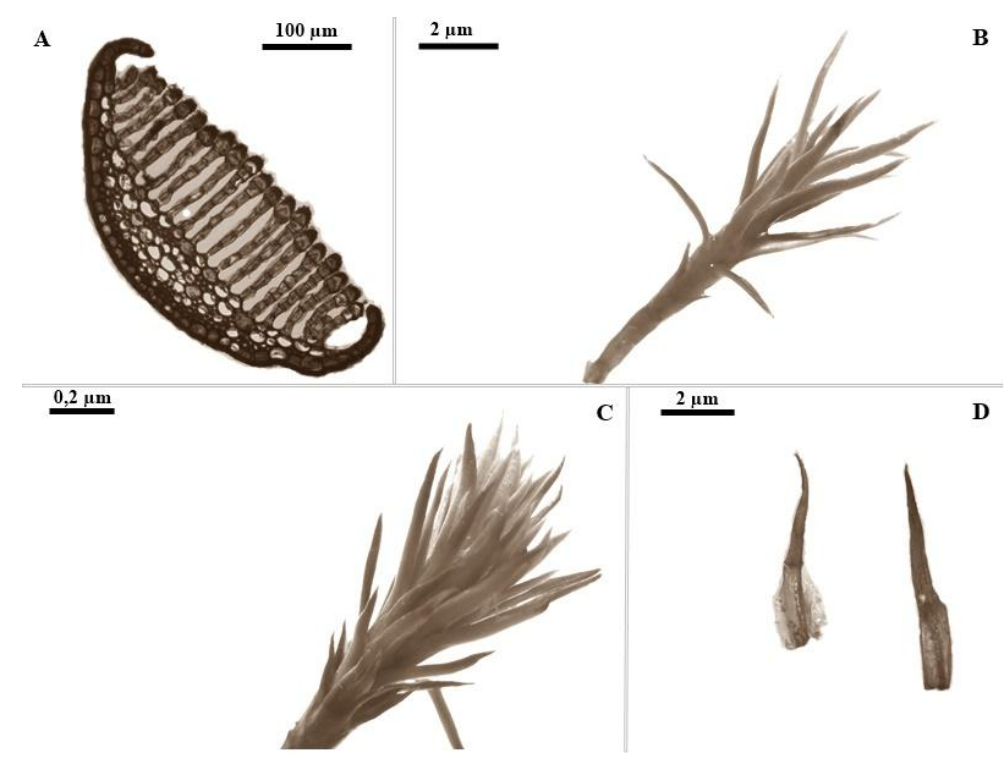

Figura 1. Polytrichastrum alpinum (Hedw.) G.L. Sm.. A. Corte transversal do filídio. B. -C. Gametófito. D. Filídios. Fonte: Mundim, J. V.

Segundo Ochyra et al. (2008) Polytrichastrum alpinum possui distribuição Bipolar Intermediária (BI-I) (Figura 2).

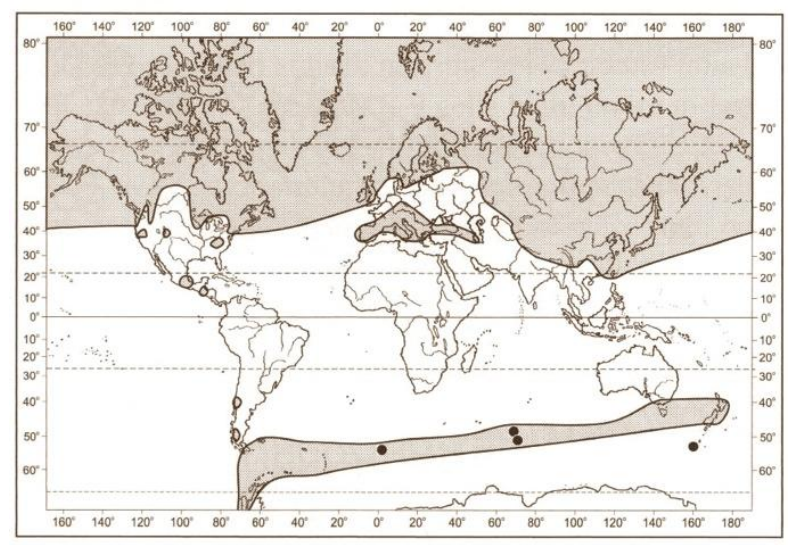

Figura 2. Mapa de distribuição de Polytrichastrum alpinum

(Hedw.) G.L. Sm.. Distribuição bipolar. Fonte: Ochyra et al (2008) 
Também são relatadas variedades para espécie Polytrichastrum. Duas descritas exclusivamente para o hemisfério norte - Polytrichastrum alpinum var. fragile (Bryhn) D.G. Long e Polytrichastrum alpinum var. sylvaticum (Menzies) G.L. Merr - e uma terceira, e Polytrichastrum alpinum var. septentrionale (Sw. ex Brid.) G.L. Sm., citada tanto para a América do Norte quanto para a Rússia (Flora of North America Editorial Committee 2007, Ochyra et al. 2008). Segundo Ochyra et al. 2008, na Antártica ocorre apenas a var. alpinum.

O objetivo desse estudo foi investigar com o uso de ferramentas morfológicas microscopia eletrônica de varredura e anatomia - se Polytrichastrum alpinum (Hedw.) G.L. Sm.. é de fato uma espécie bipolar, como proposto por Ochyra et al. (2008).

\section{Material e Métodos}

Obtenção de material - Foram recebidos empréstimos de material de $P$. alpinum proveniente do hemisfério norte, concedidos pelos herbários: AAS, BA, DUKE, HBEI, ICEL, LIL MO, NY e S (siglas segundo Thiers 2014).

Para amostras da Antártica e Chile, utilizou-se material dos herbários BA, HBEI, LIL, RB, S e SP, além de amostras coletadas (Figura 3), entre os meses de novembro de 2014 e março de 2015, na Ilha Rei George, Ilha Penguin, Ilha Ardley, Ilha Deception, Ilha Snow, Livingston e Ilha Nelson, seguindo as orientações de Yano (1984). Todo o material coletado encontra-se depositado no herbário UB.

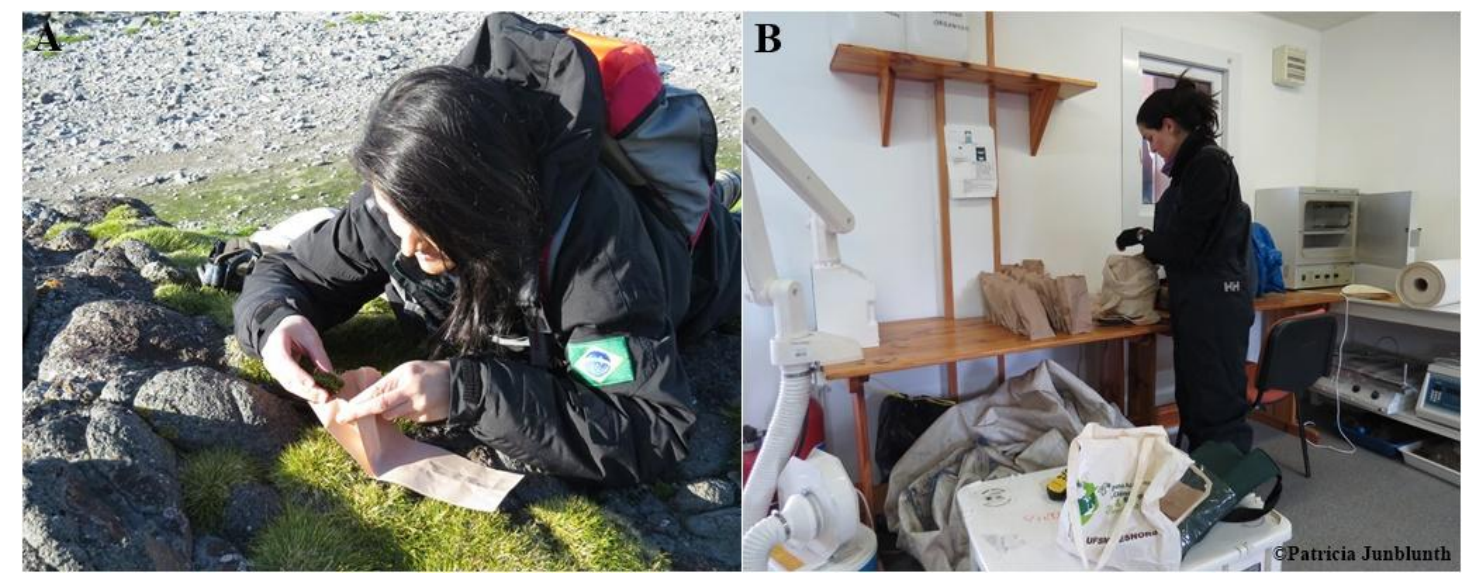

Figura 3. Expedição de campo - Antártica. A. Coleta de material na ASPA 128 ( Antarctic Special Protected Area), Ilha Rei George - Antártica; B. Secagem de material. 
Morfologia - Foram analisadas 400 amostras, 50 destas correspondentes ao material de empréstimo e as demais de material fresco coletado no continente antártico. A listagem do material examinado encontra-se no Anexo I, sendo listado um representante por localidade.

As amostras de filídios e cortes transversais foram montadas em laminas semipermanentes fixadas com Hoyer (Anderson 1954) com o auxílio de microscópio estereoscópico e observadas sob microscópio óptico, quanto as características de formato dos filídios, estruturas celulares, além do formato do corte transversal na região mediana do limbo para visualização da configuração das lamelas.

As plantas foram identificadas com base em Ochyra et al. (2008) e na Flora da América do Norte (North America Editorial Committee 2007).

Microscopia Eletrônica de Varredura - Foram utilizados 12 espécimes de $P$. alpinum, conforme Anexo II. As amostras foram preparadas segundo Bozzola \& Russel (1998), ou seja, reidratadas previamente em água destilada fervente, durante 5 minutos; passando, em seguida, por desidratação, inicialmente alcoólica, e gradualmente em série de Acetato de N - Butila, seguindo as concentrações: etanol (50\%), etanol (70\%), etanol (90\%), etanol $(100 \%)$, etanol (100\%), etanol $(100 \%) /$ acetona (100\%), acetona (100\%) e acetona (100\%), permanecendo 20 minutos em cada solução.

Ao término da desidratação, foi realizada a dessecação ao ponto crítico, através do equipamento Balzers CPD 030, utilizando $\mathrm{CO}_{2}$ líquido como fluido de transição, o material foimontado em "stubs" de cobre $(1 \mathrm{~cm}$ x $1 \mathrm{~cm})$. O material foi coberto com ouro - paladium, com uso do metalizador Blazers 050 SCD.

O material foi observado e micrografado por meio do microscópio eletrônico JSM 7100 F Foram observados os filídios com vista abaxial, adaxial e cortes na porção mediana, para visualização das lamelas.

Os processos de dessecação e metalização foram realizados no laboratório de Microscopia Eletrônica do Departamento de Biologia Celular da Universidade de Brasília e a micrografia com o auxílio do Grupo de Fadiga, Fratura e Materiais do Departamento de Engenharia Mecânica da Universidade de Brasília.

Estudo Anatômico - Filídios e caulídios de quatro amostras de Polytrichastrum alpinum (duas da Antártica e duas do hemisfério norte) foram elencados para estudo anatômico (Anexo III).

As amostras foram submetidas à série alcoólica - 90\%, 85\%, 80\%, 75\%, 70\% e 50\%; passando em seguida por água destilada, para hidratação do material. Retornando ao álcool 
70\% para conservação do mesmo (Sanderson 1994). Previamente aos procedimentos de corte, o material foi lavado e acondicionado em recipiente com água destilada por 30 minutos, para retirada do álcool. Foram elencados filídios da região mediana do gametófito, além do caulídio, também em porção mediana.

Para a montagem em Resina Sintética, foram realizadas secções transversais, nos filídios, principalmente na região das lamelas e em toda a extensão da porção mediana do caulídio. Foram obtidas por intermédio de técnica manual com auxílio de lâmina de aço inox.

Os cortes foram clarificados em solução de hipoclorito de sódio a $20 \%$, seguido por hipoclorito $50 \%$ e lavadas em água destilada e coradas em azul de alcião e safranina 3:1 (Roeser 1962). Em seguida, foram dispostos em lâminas com resina sintética (verniz vitral).

Para inclusão de material em Historresina, os filídios foram fixados em mistura de Karnovsky (Karnovsky 1965), seguindo por desidratação em etanol - 70\%, $96 \%$ e 100\%. Passando em seguida por pré-infiltração -etanol 100\% + resina líquida (1:1); infiltração em meio A (resina líquida - Glicol metacrilato; e pó ativador); finalizando com polimerizaçãoMeio B (Meio A + Hardener - endurecedor). Após o endurecimento, os materiais foram colados com cola de secagem rápida sobre blocos de madeira. O seccionamento foi realizado em micrótomo rotacional modelo SLEE MAINZ cute 5062. As amostras foram coradas e montadas em lâminas permanentes.

As fotomicrografias foram obtidas em microscópio Leica DM 750.

\section{Resultados e Discussão}

Estudo Morfológico - As amostras provenientes dos hemisférios norte e sul conferem com a descrição e as características morfológicas propostas na literatura (Flora of North America Editorial Committee 2007 e Ochyra et al. 2008) para Polytrichastrum alpinum. As amostras da Antártica apresentam menores dimensões, quando comparados ao comprimento e a largura dos filídios do hemisfério norte.

As amostras de P. alpinum coletadas na Antártica apresentam exclusivamente gametófitos masculinos, diferentemente do descrito por Ochyra et al. (2008), que relata a ocorrência de indivíduos de ambos os sexos nas populações antárticas. Nos espécimes do hemisfério norte foram observados indivíduos masculinos e femininos.

Não foram encontradas outras variedades de P. alpinum, além de Polytrichastrum alpinum var. alpinum, nas amostras analisadas. 
Microscopia Eletrônica de Varredura - A MEV evidenciou grande similaridade morfológica entre as amostras de $P$. alpinum advindas de ambos os hemisférios. Os cortes transversais dos filídios na região mediana do limbo apresentam formato similiar (Figuras 4 B 5 B), principalmente quanto ao formato curvado da última fileira de lamelas (Figuras 4 C e 5 C) característica taxonômica intrínseca da espécie. O Serrilhamento observado da Figura 5 C, também está presente nas amostras da Antártica, sendo uma característica da espécie, não amostrada em todas as imagens devido a posição no momento do corte.

Durante minuciosa observação, também foi descoberta uma discrepância entre as amostras, não visível em microscopia de luz. A face abaxial dos filídios em amostras da Antártica apresenta uma organização de linhas longitudinais em sua epiderme, enquanto aquelas oriundas do hemisfério norte possuem a superfície quadriculada (Figuras 4A e 5A).

Ponderando-se os caracteres observados em microscopia de varredura, considera-se que os pares polares de $P$. alpinum apresentam mais características que os relacionem, do que os discriminem. 


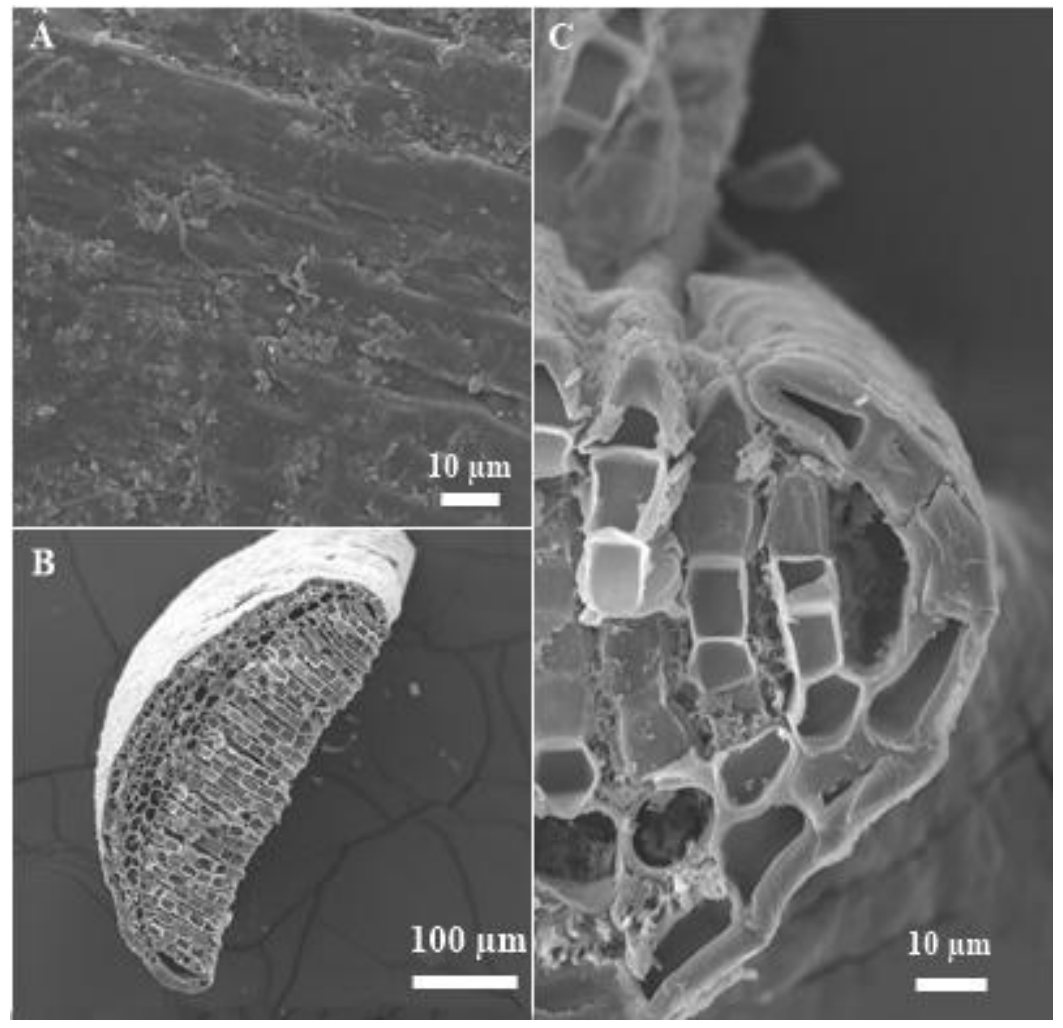

Figura 4. Microscopia Eletrônica de Varredura de Polytrichastrum alpinum G.L. Sm.. proveniente da Antártica. A) Vista abaxial; B) Corte transversal na porção mediana; C) Formato da última fileira de lamelas em corte de secção transversal. Fonte: Mundim, J. V. 


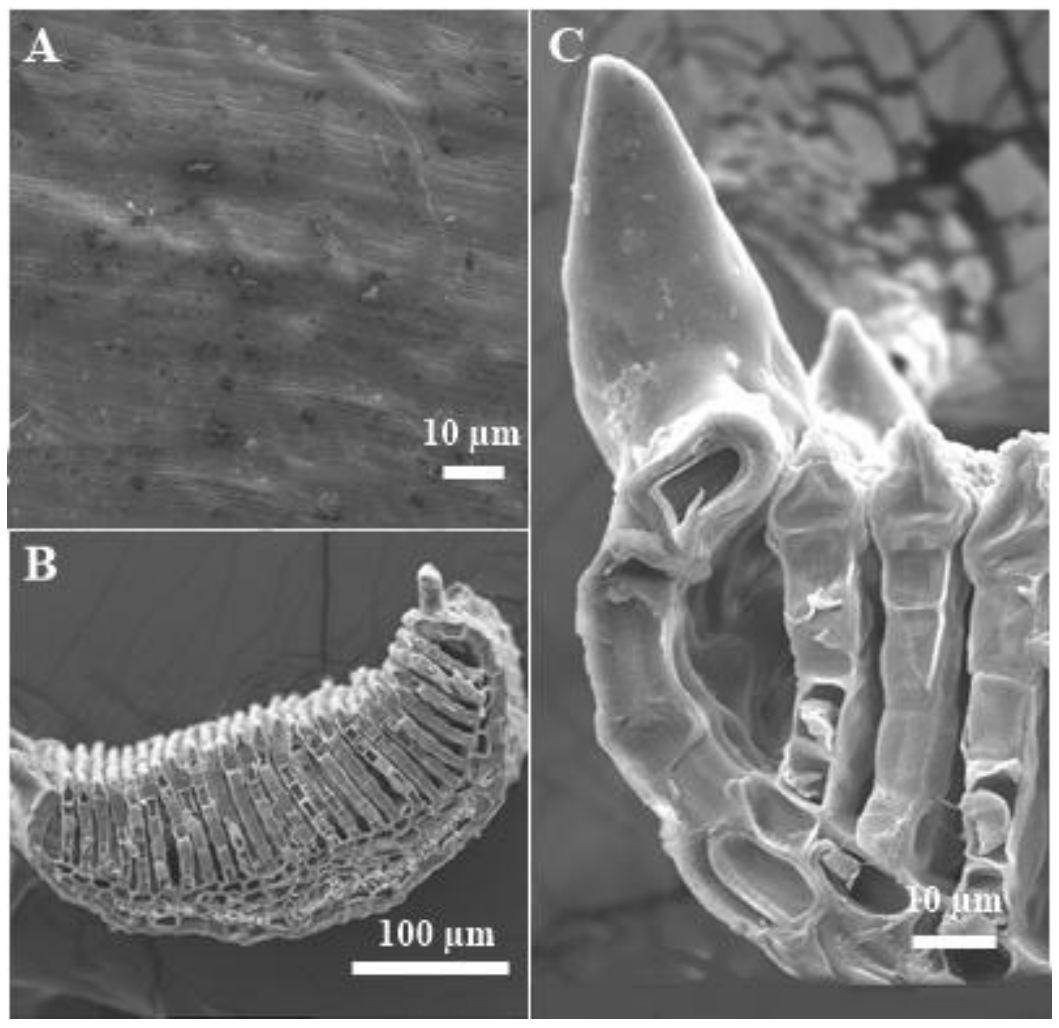

Figura 5. Microscopia Eletrônica de Varredura de amostrasPolytrichastrum alpinum proveniente do Hemisfério Norte. A) Vista abaxial; B) Corte transversal na porção mediana; C) Formato da última fileira de lamelas em corte de secção transversal. Fonte: Mundim, J. V.

Descrição anatômica - As colorações utilizadas - azul de alcião (Serrato-Valenti et al. 1992 e Srebotnik \& Messner 1994) e safranina - são responsáveis pela coloração da parede celular e de estruturas cutinizadas, respectivamente, padrão nitidamente observado nas amostras (Figuras 6 B e C; 7 B e C). Observa-se a coloração fortemente avermelhada na região abaxial dos cortes em porção mediana dos filídios, destacada da coloração azul das paredes celulares das lamelas (6 B e 7 B). 


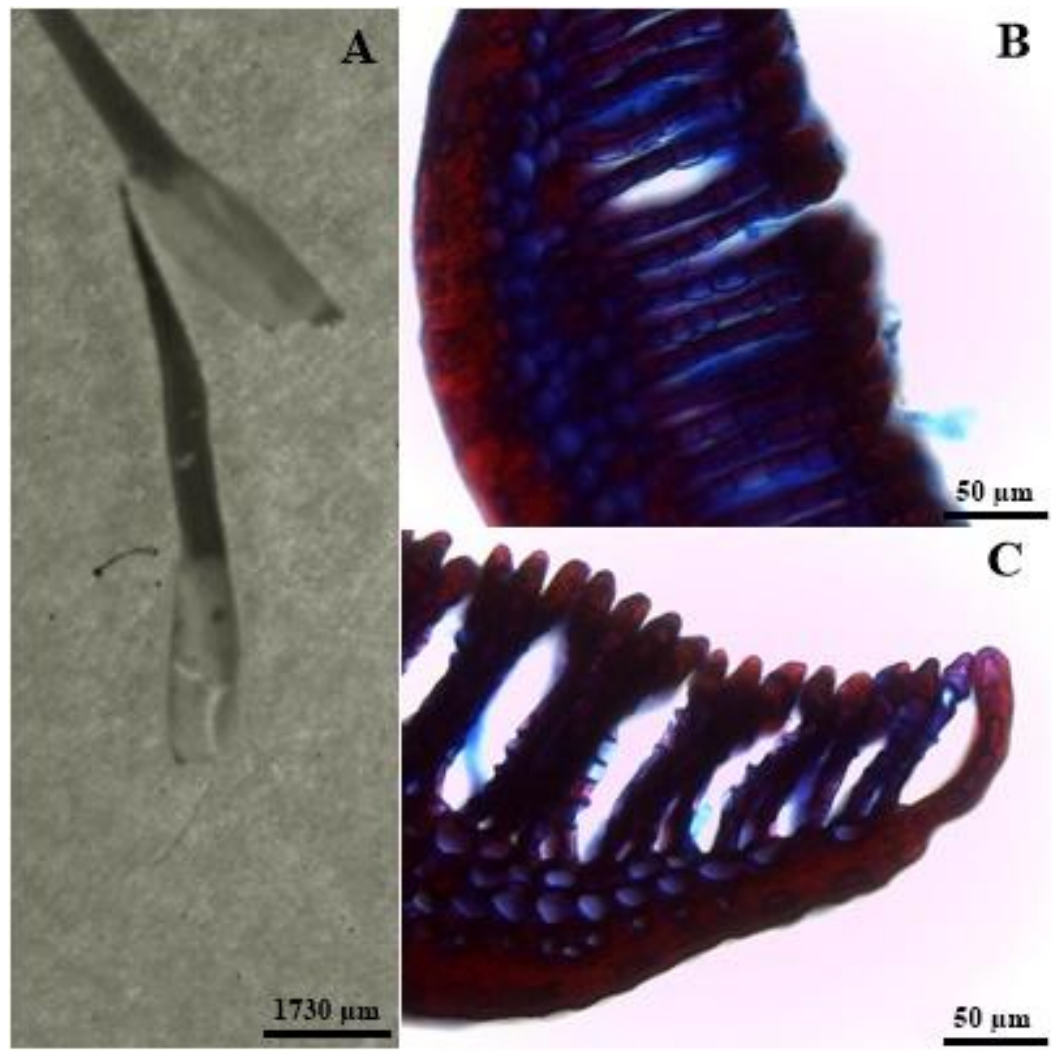

Figura 6. Polytrichastrum alpinum. A. Filídio de indivíduo da Antártica. B- C Corte anatômico de filídio para visualização das lamelas, corado com azul de alcião e safranina; Fonte:Mundim, J. V. 


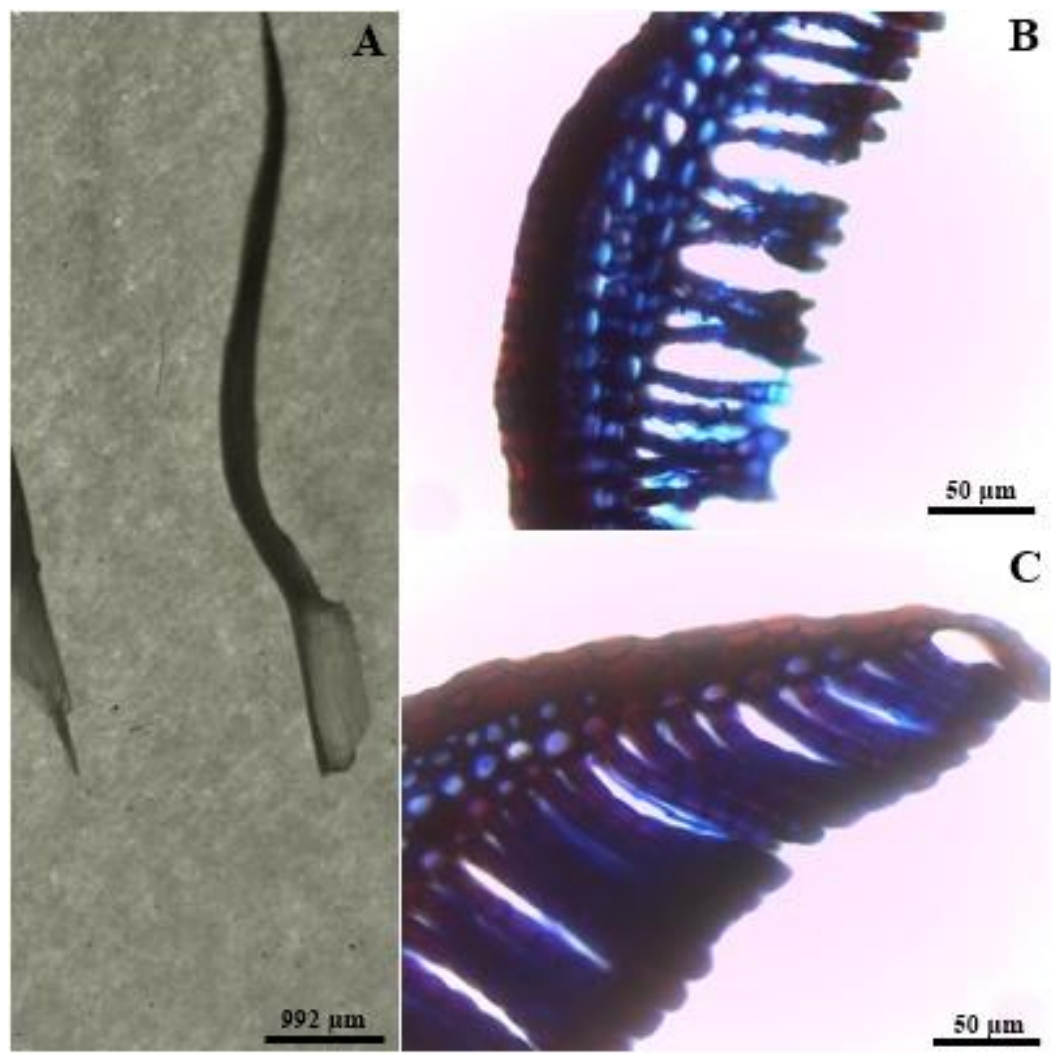

Figura 7. Polytrichastrum alpinum. A. filídio de indivíduo do Alasca.

B- C Corte anatômico de filídio para visualização das lamelas, corado com azul de alcião e safranina; Fonte:Mundim, J. V.

Nos seccionamentos transversais realizados em caulídios de $P$. alpinum, apresenta-se nítida a organização de córtex e cilindro central (Figuras 8 e 9), o que não ocorre na maioria dos musgos (Hébant 1977), e das células especializadas em condução - hidróides e leptóides (Figuras 10 e 11). 


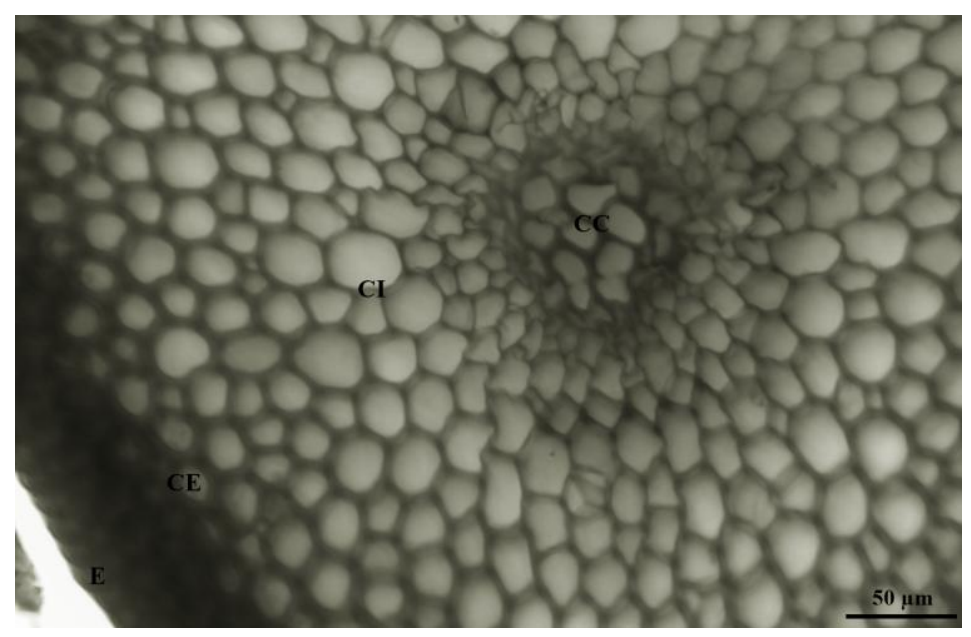

Figura 8. Corte transversal de caulídio de Polytrichastrum alpinum em indivíduo coletado na Antártica (E) - epiderme; (CE) - Córtex Externo; (CI) - Córtex Interno; (CC) - Cilindro Central; (1) - leptóides e (h) - hidroides. Fonte: Mundim, J. V.

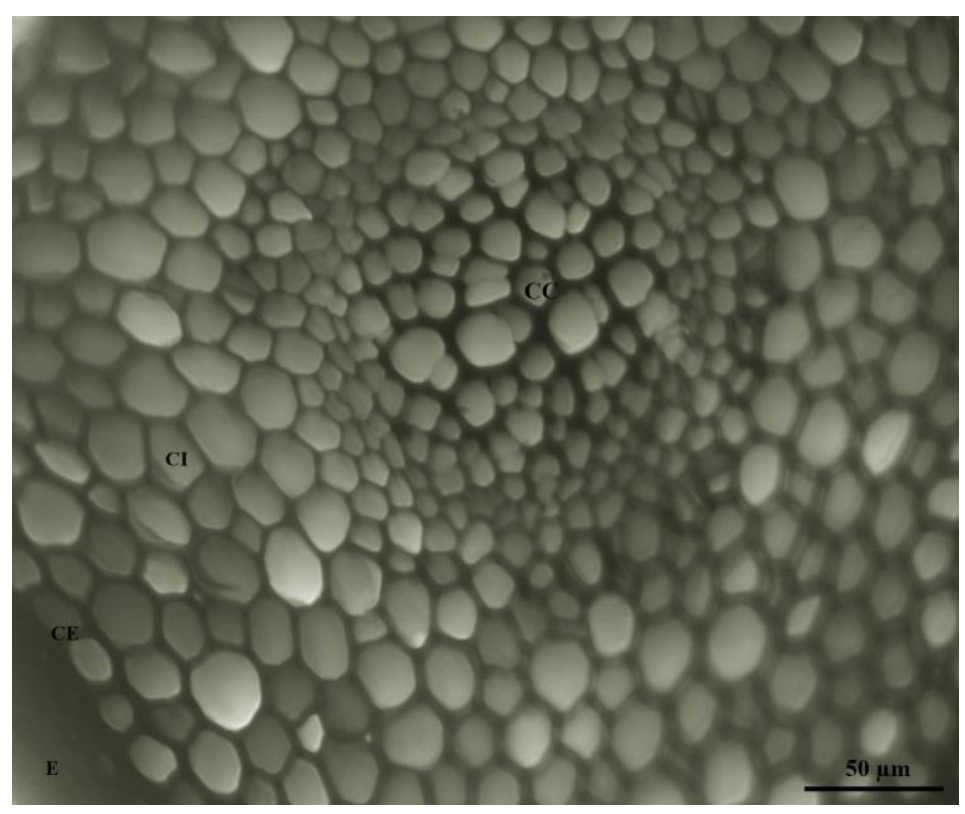

Figura 9. Corte transversal de caulídio de Polytrichastrum alpinum em indivíduo coletado no Alasca. (E) - epiderme; (CE) - Córtex Externo; (CI) Córtex Interno; (CC) - Cilindro Central; (l) - leptóides e (h) - hidroides. Fonte:Mundim, J. V.

Percebe-se uma pequena distinção entre o cilindro central (Figuras 10 e 11) da amostra Antártica e do material do Alasca. No material da Antártica, 
os leptóides apresentam-se mais agrupados, enquanto na amostra do Alasca, aparentam estar mais dispersas.

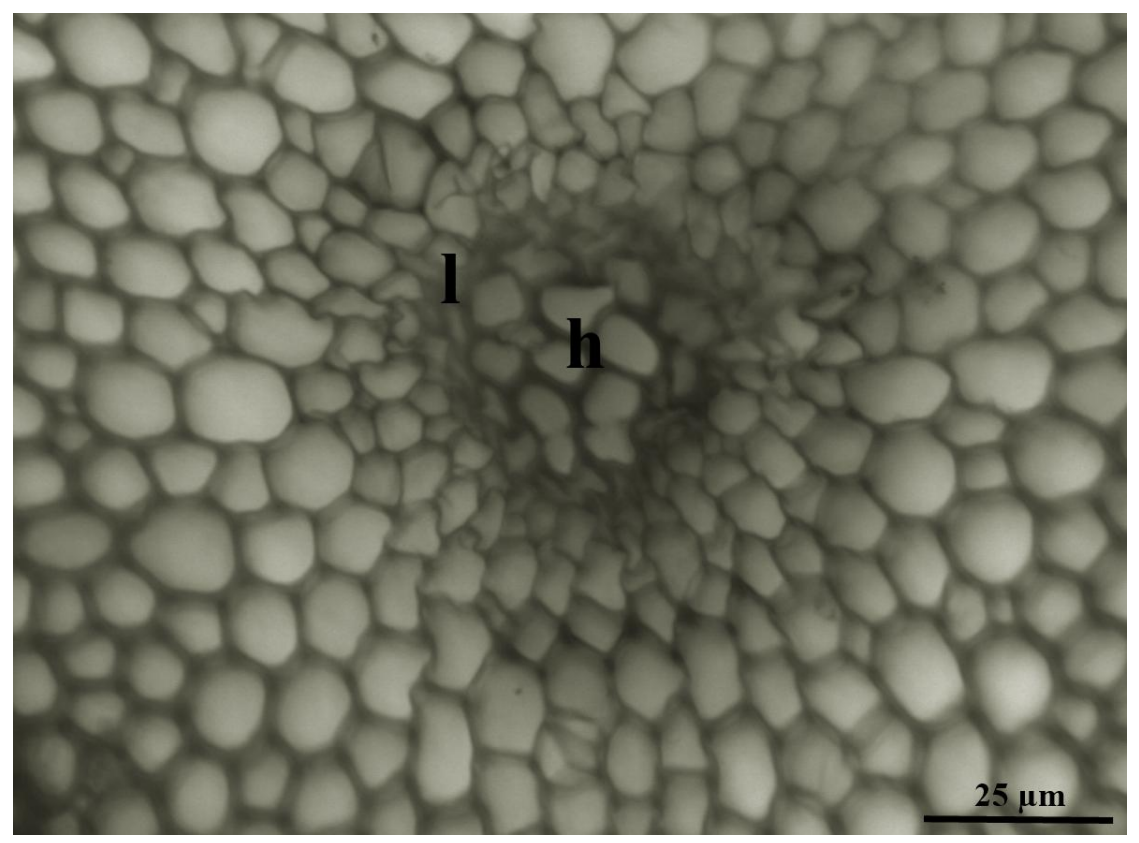

Figura 10: Corte transversal de caulídio de Polytrichastrum alpinum - indivíduo coletado na Antártica. (h) - hidróides e (1) - leptóides. Fonte: Mundim, J. V.

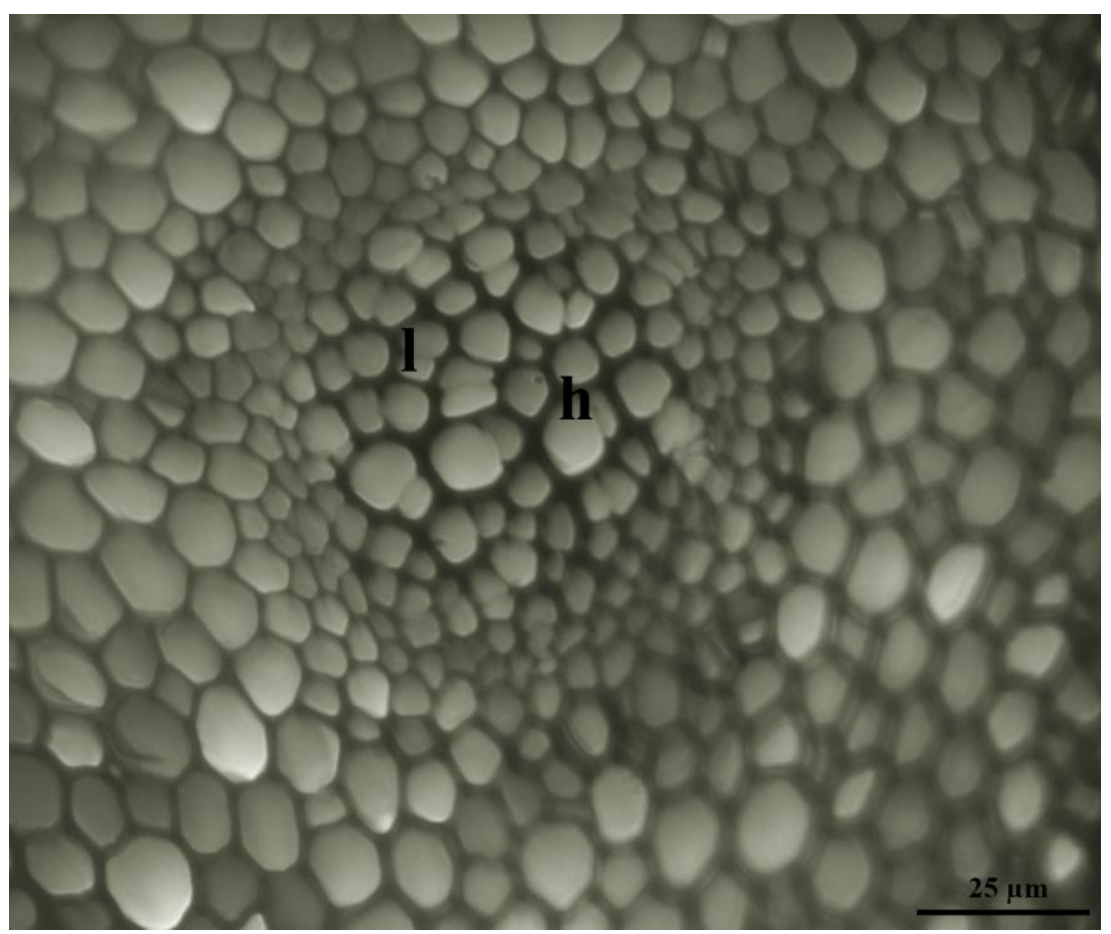

Figura 11: Corte transversal de caulídio de Polytrichastrum alpinum -indivíduo coletado na Alasca. (h) - hidróides e (l) - leptóides. Fonte: Mundim, J. V. 
Existem dois estudos envolvendo anatomia de Polytrichaceae, ambos relacionados ao caulídios de Dendroligotrichum dendroides (Brid. ex Hedw.) Broth. (Atala 2011, Scheirer 2015). No entanto, não foram observados trabalhos que utilizem técnicas de coloração para a anatomia de filídios.

\section{Considerações Finais}

Apesar de terem sido observadas algumas discrepâncias entre os espécimes, sugere-se que sejam em função das condições climáticas diferenciadas entre os locais de ocorrência.

A Antártica é o local mais extremo e isolado do planeta, apresentando os menores índices de umidade, as menores temperaturas já registradas no planeta Terra, os maiores níveis de incidência de raios ultravioleta (Raios-UV) e as mais velozes rajadas de vento (Longton \& Holdgate 1979). Mediante tais condições, a flora antártica é diferenciada da ártica, sendo predominantemente criptogâmica, com apenas duas espécies de angiospermas. Já a região ártica possui temperaturas mais amenas que a Antártica, maior umidade, menor incidência de Raios -UV (Corell, R. 2012), e uma flora com mais de 900 espécies de angiospermas (Love \& Love).

As diferenças entre essas regiões pode ser capazes gerar adaptações às exigências dos respectivos ambientes, podendo ser uma explicação para as pequenas diferenças observadas.

Portanto, infere-se que as análises realizadas em espécimes de Polytrichastrum alpinum, corroboram com a proposta de bipolar intermediária indicada por Ochyra et al. (2008). 


\section{Referências Bibliográficas}

Anderson, L. E. 1954. Hoyer's solution as a rapid permanent mounting medium for bryologists. The Bryologist volume 57 páginas 242-244.

Atala, C. 2011. Water transport and gas exchange in the non-vascular plant Dendroligotrichum dendroides (Brid. ex Hedw.) Broth. (Polytrichaceae, Bryophyta). Gayana Bot. 68(1): 89-92.

Bozolla, J.J. Rusell, L.D. 1998. Electron Microscopy, principles and tecnhiques for biologists. $2^{\text {nd }}$ edition. Jones \&Bartlett, Sudbury, MA.

Buck. W.R. \& Goffinet, B. 2000. Morphology and classification of mosses. In: SHAW, A. J. \& Goffinet, B. Bryophyte Biology. Cambridge: University Press Cambridge, cap. 3, p. 113.

Corell, R. 2012. Arctic Climate Impact Assessment (ACIA). Chapter 2- Arctic Climate: Past and Present Lead. Disponível em: <http://www.acia.uaf.edu/PDFs/ACIA_Science_Chapters_Final/ACIA_ Ch02_Final.pdf>.

Flora of North America Editorial Committee. 2007. Flora of North America. Bryophytes: Mosses, part 1. New York, Oxford University Press.

Hammer, Ø. \& Harper, D.A.T., Ryan, P.D. 2001. PAST: Paleontological statistics software package for education and data analysis. $\begin{array}{llll}\text { Palaeontologia } & \text { Electronica } & \text { 9pp. http://palaeo- }\end{array}$ electronica.org/2001_1/past/issue1_01.htm

Hébant, C. 1977. The Conducting Tissues of Bryophytes, Cramer, Vaduz.

Karnovsky, M. J. 1965. A formaldehyde-glutaraldehyde fixative of high osmolality for use in electron microscopy. Journal of Cell Biology 27: 
$137-138$.

Longton, R. E. \& Holdgate, M. W.. 1979. The South Sandwich Islands: 4. Botany. Brit. Antarct. Surv. Sci.. Cambridge University Press.

Love, A \& Love, D.. 1975. Cytotaxonomical atlas of the Artic Flora. Vaduz: J. Cramer XXIII, 598p. Map, chrom. Nos. Maps. Chromosome numbers.

Ochyra, R., Lewis Smith, R.I. \& Bednarek-Ochyra H. 2008.The illustrated moss flora of Antarctica. Cambridge: Cambridge University Press.

Roeser, K. R. 1962. Die nadel der schwarzkiefer massenprodukt und kunstwerk der natur. Mikrokosmos 61(2): 33-36.

Sanderson, J. B. 1994. Biological Microtechnique. RMS Microscopy handbooks 28. BIOS Scientific Publishers 224 pp.

Serrato- Valenti, G; Cornara, L. Lolito, S \& Quagliotti, L. 1992. Seed coat structure and histochemistry of Abelmosehus eseulentus: chalazal region and water entry. Ann. Bot. (Lond.) 69: 313-321.

Scheirer, D. 2015. Conditions Anatomical Studies in the Polytrichaceae. I. The Gametophore of Dendroligotrichum dendroides (Hedw.) Broth.. The Bryologist 75: 305-314.

Smith, G.L. 1971. Conspectus of the genera of Polytrichaceae. Memoirs of The New York Botanical Garden 21(3): 1-83.

Srebotnik, E. \& Messner, K. 1994. A simple method that uses differential staining and light microscopy to assess the selectivity of wood delignification by white rot fungi. App. Envirol1. Mierobiol. 60: 13831386. 
Thiers, B. 2014. Index Herbariorum: A global directory of public herbaria and associated staff. New York Botanical Garden's Virtual Herbarium. Disponível em: <http://sweetgum.nybg.org/ih/>.

Yano, O. 1984. Briófitas. Pp. 27-30. In: O. Fidalgo\& V.L.R. Bononi (coords.). Técnicas de coleta, preservação e herborização de material botânico. São Paulo, Instituto de Botânica de São Paulo, Série Documentos. 


\section{CAPÍtULLO II}

Estudos Moleculares de Polytrichastrum alpinum (Hedw.) G.L. Sm., uma Espécie Bipolar Antártica 


\section{Estudos Moleculares de Polytrichastrum alpinum (Hedw.) G.L. Sm., uma Espécie Bipolar Antártica}

Júlia Viegas Mundim ${ }^{1}$, Tamara Silva Dantas ${ }^{1}$, Paulo Eduardo Saraiva Câmara Aguiar $^{1}$

${ }^{1}$ Universidade de Brasília, Instituto de Ciências Biológicas, Departamento de Botânica

\section{Resumo}

A Antártica, toda região ao sul do paralelo $60^{\circ}$, é uma região que apresenta características inóspitas para a maioria dos seres vivos, como baixas temperaturas e umidade. As criptógamas são predominantes nesta região, sendo 110 espécies de musgos, 50 destes bipolares. Dentre estas espécies se encontra Polytrichastrum alpinum (Hedw.) G.L. que apresenta distribuição bipolar intermediária, ou seja, ocorre em ambos os polos e nas regiões tropicais de altas altitudes. Ainda existem poucos estudos sobre a diversidade genética das espécies ocorrente na Antártica e qual a relação destas com seus pares do Ártico. Portanto, o objetivo deste estudo foi utilizar ferramentas moleculares para investigar a distribuição bipolar de $P$. alpinum. $\mathrm{O}$ marcador molecular utilizado para as análises foi o trnL-F e foram utilizadas amostras oriundas de ambos hemisférios. Foram feitas análises filogenéticas, análise de diversidade haplotípica e análise de diversidade intraespecífica e as três análises corroboram a hipótese de que $P$. alpinum é uma espécie bipolar.

Palavras chave: Antártica, bipolaridade, estudo molecular, trnL-F.

\section{Abstract}

Antarctica, the entire area south of the $60^{\circ}$ parallel, is a region with 
inhospitable characteristics for most living things, such as low temperatures and humidity. The cryptogams are prevalent in this region, are found 110 species of mosses, 50 of these bipolar. Among these species is Polytrichastrum alpinum (Hedw.) GL that displays intermediate bipolar distribution, namely occurs in both poles and tropical regions of high altitudes. There are few studies on the genetic diversity of the species occurring in the Antarctic and what their relationship to their Arctic pairs. Therefore, the aim of this study was to use molecular tools to investigate the bipolar distribution of $P$. alpinum. The molecular marker used for the analyzes was the $\operatorname{trn} \mathrm{L}-\mathrm{F}$ and samples were used coming from both hemispheres. Phylogenetic analyzes were made, haplotype diversity analysis and intraspecific diversity analysis and three analyzes confirm the hypothesis that $P$. alpinum is a bipolar species.

Key words: Antarctica, bipolarity, molecular study, trnL-F.

\section{Introdução}

A Antártica corresponde a toda região ao sul do paralelo $60^{\circ} \mathrm{S}$, totalizando a extensão aproximada de 14 milhões de $\mathrm{km}^{2}$ (Brasil 2014). Continente dos superlativos, Antártica, apresenta baixas temperaturas e umidade reduzida, configurações inóspitas para a maior parte dos seres vivos, suportadas, porém, por indivíduos denominados extremófilos, capazes de desenvolver-se e se estabelecer em ambientes com tais especificidades (Longton \& Holdgate 1979, Brasil 2014).

Sua flora é predominantemente criptogâmica, composta por 110 espécies de musgos, 11 delas endêmicas e 50 bipolares (Ochyra et al. 2008, Øvstedal \& Lewis Smith 2001, Spielmann \& Pereira 2012). Espécies bipolares são aquelas compostas por indivíduos semelhantes morfologicamente e que estão distribuídos em ambas às regiões polares (Ártico e Antártico), podendo ou não apresentar ocorrências intermediárias (Ochyra et al. 2008).

Apesar do conhecimento sobre brioflora antártica (Ochyra 1998, Putzke \& Pereira 2001, Ochyra et al. 2008), são escassos os estudos sobre a diversidade genética das espécies. As espécies descritas bipolares formam ou 
não clados monofiléticos? Existem espécies crípticas? Qual a relação das espécies antárticas com seus pares da região ártica? Qual a história de dispersão dessas espécies?

Dentre os trabalhos realizados com espécies descritas bipolares, podese citar Campylopus pyriformis (Schultz) Brid. (BI-I), que segundo Stech \& Wagner 2005 e Stech et al. 2010, teve seus exemplares árticos e antárticos diferenciados em dois clados distintos e ainda mesclados com espécimes de $C$. fragilis (Brid.) Bruch \& Schimp (de regiões temperadas e tropicais).

Já o estudo realizado com Sanionia georgicouncinata (Müll. Hal.) Ochyra \& Hedenäs, que até então era considerada como BI-I, apresentou divisão em dois clados, sendo o clado do hemisfério norte correspondente morfologicamente a $S$. nivalis Hedenäs, e ambos inclusos no clado de $S$. uncinata (Hedw.) Loeske, esclarecendo que, na verdade, se tratara de uma espécie com distribuição bem mais ampla (Hedenäs 2012). Além disso, pode-se concluir que no caso de S. uncinata, provavelmente diversas linhagens tenham evoluído independentemente no hemisfério sul e que essas espécies teriam vindo do hemisfério norte, chegado à Antártica pelas vias Americana e Asiáticas.

Kato et al. (2013) realizaram estudos filogenéticos com Leptobryum wilsonii (Mitt.) Broth., de lagos da Antártica, e evidências moleculares e geohistóricas sugerem que a imigração ocorreu durante o Holoceno através da dispersão por longa distância da América do Sul. E Pisa et al.(2014) sugerem que Bryum argentum Hedw. Teria permanecido durante a glaciação, mas que também haveria ocorrido migração pós glaciação.

Dentre as espécies bipolares intermediárias está Polytrichastrum alpinum (Hedw.) G.L. Sm., representante de Polytrichaceae (Ochyra et al. 2008) (Figura 1). Segundo Bell e Hyvönen (2010 a, 2010 b) Polytrichastrum é um gênero polifilético e os representantes $P$. alpinum oriundos do hemisfério norte correspondem à mesma espécie. Ivanova et al (2014) também estudaram Polytrichastrum, mas com enfoque na brioflora russa, corroborando que Polytrichastrum alpinum é uma espécie monofilética. 


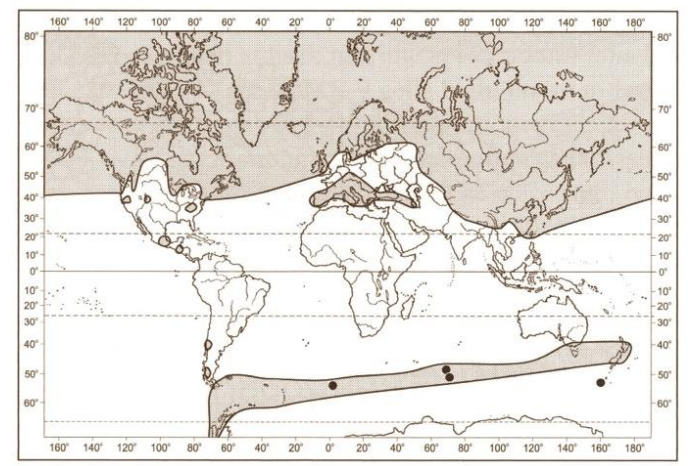

Figura 1. Mapa da Distribuição Bipolar de

Polytrichastrum alpinum (Hedw.) G.L. Sm..

Fonte: Ochyra et al (2008).

Polytrichastrum alpinum é uma planta acrocárpica robusta, considerada um dos maiores representantes de musgos existentes, variando de 4 a $6 \mathrm{~cm}$ de comprimento, mas excepcionalmente chegando a $13 \mathrm{~cm}$ (Ochyra 2008).

São apresentadas na literatura variedades de $P$. alpinum, sendo duas relatadas exclusivamente para o hemisfério norte - Polytrichastrum alpinum var. fragile (Bryhn) D.G. Long e Polytrichastrum alpinum var. sylvaticum (Menzies) G.L. Merr - e Polytrichastrum alpinum var. septentrionale (Sw. ex Brid.) G.L. Sm com ocorrência na América do Norte e Rússia (Flora of North America Editorial Committee 2007, Ochyra et al. 2008). E a variedade alpinum, que é bipolar.

O objetivo do estudo foi investigar com o uso de ferramentas moleculares se Polytrichastrum alpinum (Hedw.) G.L. Sm.. é de fato uma espécie bipolar, como sugerido por Ochyra (2008).

\section{Material e Métodos}

Extração e amplificação- O DNA foi extraído de material fresco obtido durante as coletas de campo na Antártica, entre os meses de novembro de 2014 e março de 2015. As amostras selecionadas foram previamente limpas com auxilio de um pincel e água, para retirada de resquícios de solo e outras impurezas; posteriormente foram acondicionadas em sílica gel para retirada da umidade e facilitação da extração. A obtenção do DNA deu-se por meio do protocolo de mini-CTAB (Doyle \& Doyle 1987) com adaptações de Câmara 
(2010).

Foi amplificado o marcador cloroplastial trnL-F (Taberlet et al. 1991), por intermédio da técnica de Reação em Cadeia de Polimerase (PCR Polymerase Chain Reaction) (Mullis \& Faloona 1987). A escolha do marcador deu-se em função de sua utilização em diversos trabalhos com briófitas (e.g. Stech et al 2005, 2010, 2013; Hedenäs 2012), inclusive em trabalhos com o gênero Polytrichastrum (Bell \& Hyvönen 2010 a, b). Foram utilizadas 54 Sequencias já disponíveis do GenBank - NCBI (anexo IV). O grupo externo foi escolhido baseado em Bell \& Hyvönen (2010 a, b) e está contabilizado nas oriundas do GenBank.

O protocolo de PCR seguiu o padrão para $50 \mu \mathrm{l}$ de solução, contendo $5 \mu 1$ de $\mathrm{Mg}$ buffer, $5 \mu 1 \mathrm{MgCl}_{2}, 2 \mu \mathrm{l} \mathrm{BSA}, 4 \mu \mathrm{dNTP} \operatorname{mix}, 0.5 \mu \mathrm{l}$ Taq polimerase e 2,5 $\mu 1$ de cada primer, $2 \mu 1$ de DNA e 26,5 $\mu 1$ de água Milli-Q.

Para amplificação foi utilizado o ciclo: $95^{\circ} \mathrm{C}(1 \mathrm{~min}), 50-54^{\circ} \mathrm{C}(1 \mathrm{~min})$ e $72^{\circ} \mathrm{C}(1 \mathrm{~min})$ por 35 ciclos, sempre precedido por desnaturação - 1 minuto a $95^{\circ} \mathrm{C}$; alongamento final -7 minutos a $72^{\circ} \mathrm{C}$. O processo de amplificação foi efetuado no Laboratório de Biologia Molecular de Plantas do Departamento de Botânica da Universidade de Brasília e o produto de PCR encaminhado Macrogen Inc., para limpeza e sequenciamento.

Análise de dados - Obtidas todas as sequências utilizou-se o programa Geneious (Kearse et al., 2012) para a montagem e edição destas, e realizado o alinhamento automático através do CLUSTALX 2.1 (Higgins \& Sharp 1988) e ajuste manual com o uso do programa PHYDE (Müller et al 2006). As inserções e deleções foram codificadas utilizando o programa Seqstate ver. 1.4.1 (Müller 2005).

Foram empregadas análises de Máxima Parcimônia (MP), Máxima Verossimilhança (MV) e Inferências Bayesianas (IB).

A Análise de MP foi efetuada do software PAUP v.4.0b10 (Swofford 2002). A Busca heurística foi realizada com 100 replicações randômicas e com 10.000 árvores. Os caracteres foram desordenados e igualmente ponderados e os gaps foram tratados como ausência de dados. O bootstrap foi calculado como parâmetro de suporte para os clados (Felsenstein 1985), com 1.000 replicações. 
A análise de MV foi realizada no software RaxML. (Stamatakis 2014). O suporte para os clados foi calculado utilizando bootstrap não paramétrico (Felsenstein 1985), com 1.000 replicações. O modelo evolutivo mais apropriado para a matriz gerada foi escolhido através do programa JmodelTest v.2.1.3 (Darriba et al. 2012).

As inferências Bayesianas foram feitas no software Mr. Bayes v.3.2.6 (Ronquist \& Huelsenbeck 2003) O suporte para os nós foi calculado por meio das probabilidades posteriores. Os valores das probabilidades posteriores variam entre 0 e 1 . O modelo evolutivo mais apropriado para a matriz foi gerado utilizando o software jModeltest 2.1.3 (Darriba et al. 2012). Tais análises fora processadas em quatro corridas, cada uma com duas cadeias MCMC (Markov Chain Monte Carlo) foram executadas para 5.000.000 gerações, amostradas a cada 1.000 gerações e em corridas paralelas. Os primeiros $25 \%$ das árvores foram descartados (burn-in).

A árvore consenso (majority rule) foi construída. O software Tracer 1.5 (Rambaut \& Drummond 2013), foi utilizado para determinar quando a amostragem das árvores estava estabilizada.

As características das análises MP, MV e inferências bayesianas da região $\operatorname{trn} \mathrm{L}-\mathrm{F}$ foram sumarizadas no anexo $\mathrm{V}$.

Diversidade Haplotípica - A rede de haplótipos, representação da diversidade genética, foi utilizada em complementação a filogenia, para o entendimento das relações entre os representantes de Polytrichastrum alpinum advindos de diferentes localidades.

Foi realizado alinhamento das sequências (mesmas sequências de $P$. alpinum presentes nas análises filogenéticas) por meio do software PHYDE (Müller et al 2006).

Para efetuar a análise de diversidade haplotípica, as sequências alinhadas foram submetidas aos programas DNAsp v.: 5.10.1 (Rozas et al 2010) e PopArt (http://popart.otago.ac.nz)., gerando a rede de haplótipos.

Diversidade Intraespecífica - Análises de diversidade são aliadas de diversos estudos moleculares desde mecanismo de avaliação na variabilidade genética em espécies de briófitas (Weitz \& Heyn 1981; Werner et al. 2005; Spagnuolo et al 2007; Spagnuolo et al 2009 ; Lang \& Naciri 2009) até mesmo 
como ferramenta de avaliação de marcadores ideais para identificação da biodiversidade por meio de DNA Barcode (Januário, Cicarelli \& Silva 2009).

No presente estudo, a diversidade intraespecífica foi utilizada em exemplares de $P$. alpinum de diversas localidades (mesmos exemplares da filogenia), buscando identificar as variações existentes entre estas.

Foi utilizado para esta análise o software PAUP v.4.0b10 (Swofford 2002).

\section{Resultados e Discussão}

Análises moleculares - Foram amplificadas duas amostras oriundas da Antártica utilizando o marcador molecular trnLF. Os demais acessos foram obtidos através do banco de dados (GenBank).

As árvores obtidas em cada análise apresentaram a mesma topologia, diferindo somente no grau de resolução dos nós, demonstrando a consistência dos dados e das análises realizadas. As árvores bayesianas apresentaram convergência.

As análises filogenéticas (Figura 2) realizadas com o marcador trnL-F mostraram que espécimes de Polytrichastrum alpinum formam um clado monofilético. As amostras de ambos os hemisférios pertencem ao mesmo clado, sugerindo que sejam de fato a mesma espécie.

Segundo Bell \& Hyvönen (2010 a) Polytrichastrum alpinum é monofilético, com clado formado por amostras do Chile, Finlândia, Nova Zelândia, Noruega e Reino Unido, não sendo amostrados espécimes da Antártica. No presente estudo, mesmo com a inserção de sequências da Antártica, Estados Unidos e Rússia, $P$. alpinum permaneceu monofilético, não havendo separação de clados relacionados com a distribuição geográfica das amostras, quando comparados os dois hemisférios, o que corrobora a hipótese de Ochyra et al (2008), de que P. alpinum é bipolar.

Diferentemente do observado por Stech \& Wagner (2005) e Stech et al. (2010), nos quais as espécies anteriormente consideradas bipolares passaram a corresponder a distribuição mais ampla, Polytrichastrum alpinum permanece com a classificação bipolar. 


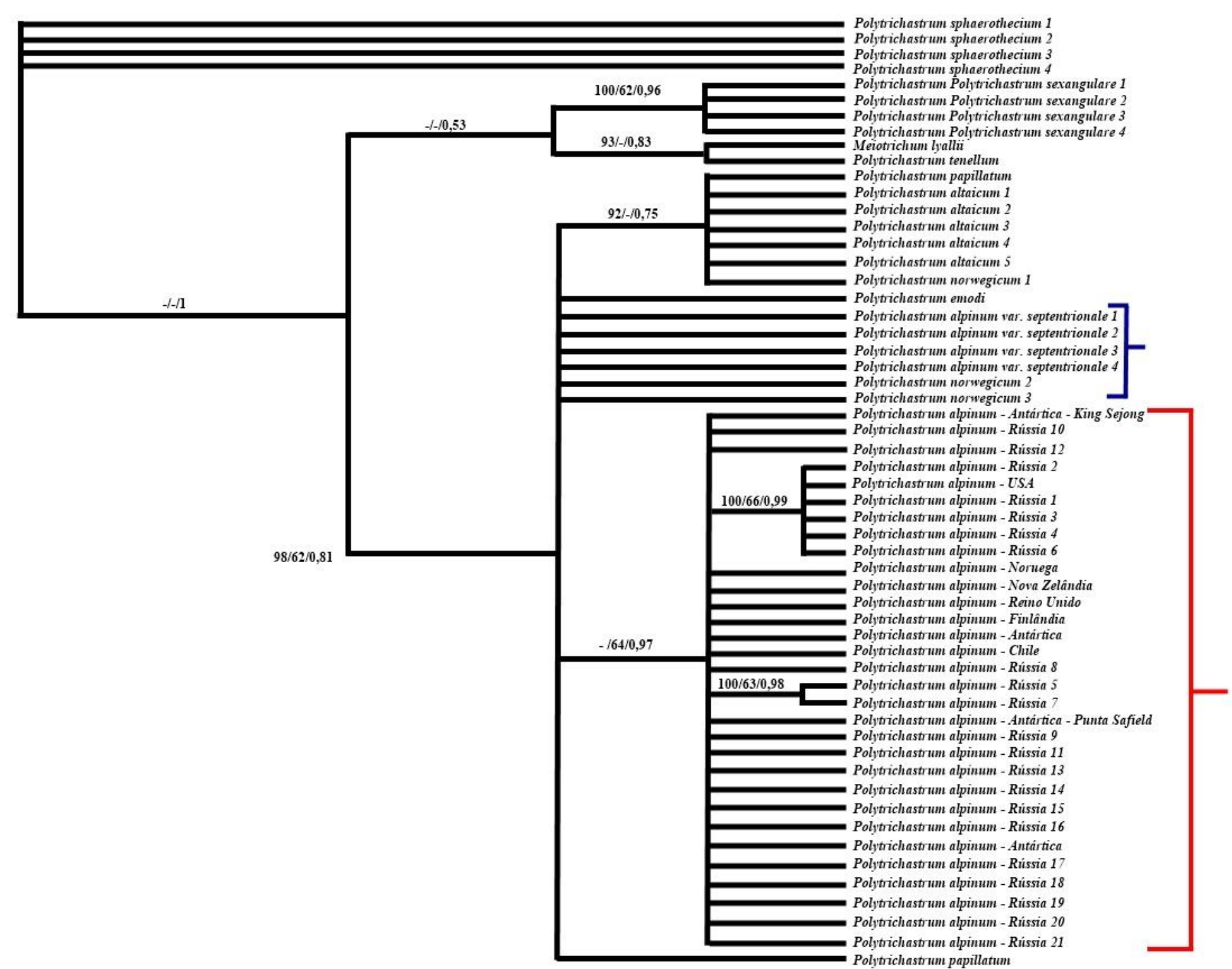

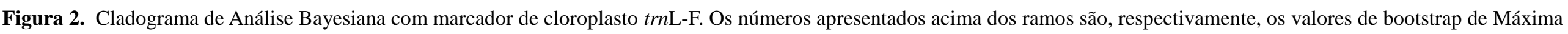

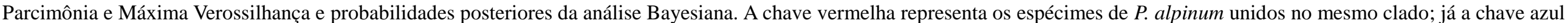
evidencia a var. septentrionale disposta num clado distinto àquele de P. alpinum. Fonte: Mundim, J. V. 
Ainda com relação à Polytrichastrum alpinum var. septentrionale - apresentada na Flora of North America Editorial Committee (2007) como uma das variedades de P. alpinum, porém, considerada por Bell \& Hyvönen (2010 a, b) como P. norwegicum, em virtude do que declaram ser erro nomenclatural - as amostras mostram-se mais próximas filogeneticamente a $P$. altaicum. Nas análises aqui realizadas (com sequências de ambas designações, segundo nominação disposta no GenBank), tanto $P$. alpinum var. septentrionale quanto Polytrichastrum norwegicum divergem de P. alpinum, apresentando-se em um clado distinto.

Ao realizar-se o alinhamento das sequências, pôde-se observar uma mutação na posição 269, ocorrente apenas nas plantas denominadas $P$. alpinum, o que as difere das demais espécies do gênero Polytrichastrum e de Meiotrichum lyallii (Mitt.) G.L. Merr.. P. alpinum apresenta a base nitrogenada adenina, enquanto as outras espécies uma guanina. Polytrichastrum alpinum var. septentrionale não apresenta a mutação.

Diversidade Haplotípica - A análise de diversidade haplotípica mostra um haplótipo formado por dois exemplares da Antártica, quatro da Rússia, um do Chile e um da Finlândia; outro haplótipo composto por um espécime antártico e três russos; quatro haplótipos diferentes formados exclusivamente por indivíduos da Rússia; e um último agrupando exemplares da Noruega, Nova Zelândia e Reino Unido (Figura3).

Ivanova et al (2014) no mesmo estudo em que averiguaram a filogenia de Polytrichastrum da Rússia, também constroem uma rede de haplótipos para o gênero. Os resultados indicam que a amostra de Polytrichastrum alpinum oriunda do Chile possui o mesmo haplótipo que uma amostra da Finlândia e cinco da Rússia. Nessa rede de haplótipos não foi amostrada a Antártica, ao contrário de sua filogenia que inclui um espécime.

$\mathrm{Na}$ análise aqui realizada foram incluídas três sequências da Antártica, duas destas alocadas no mesmo grupo formado por Chile, Finlândia e Rússia, corroborando com o apresentado por Ivanova et al (2014).

É possível observar na rede de haplótipos que as amostras do hemisfério sul (Antática - King Sejong; Antártica - Punta Safield; Chile) compartilham o mesmo haplótipo que alguns espécimes do hemisfério norte (Finlândia e Rússia), ou seja, apresentam-se geneticamente iguais na região averiguada $(\operatorname{trn} \mathrm{L}-\mathrm{F})$.

Acredita-se ainda, que hajam diferentes haplótipos dos espécimes de $P$. alpinum da Antártica devido à colonização da espécie ter ocorrido em momentos distintos, similar ao ocorrido com Bryum argentum Hedw., que teria uma colonização pré glaciação, tendo 
ocorrido também migração após esse período (Pisa et al. 2014). Essa é uma hipótese que pode ser averiguada a partir de estudos filogeográficos.

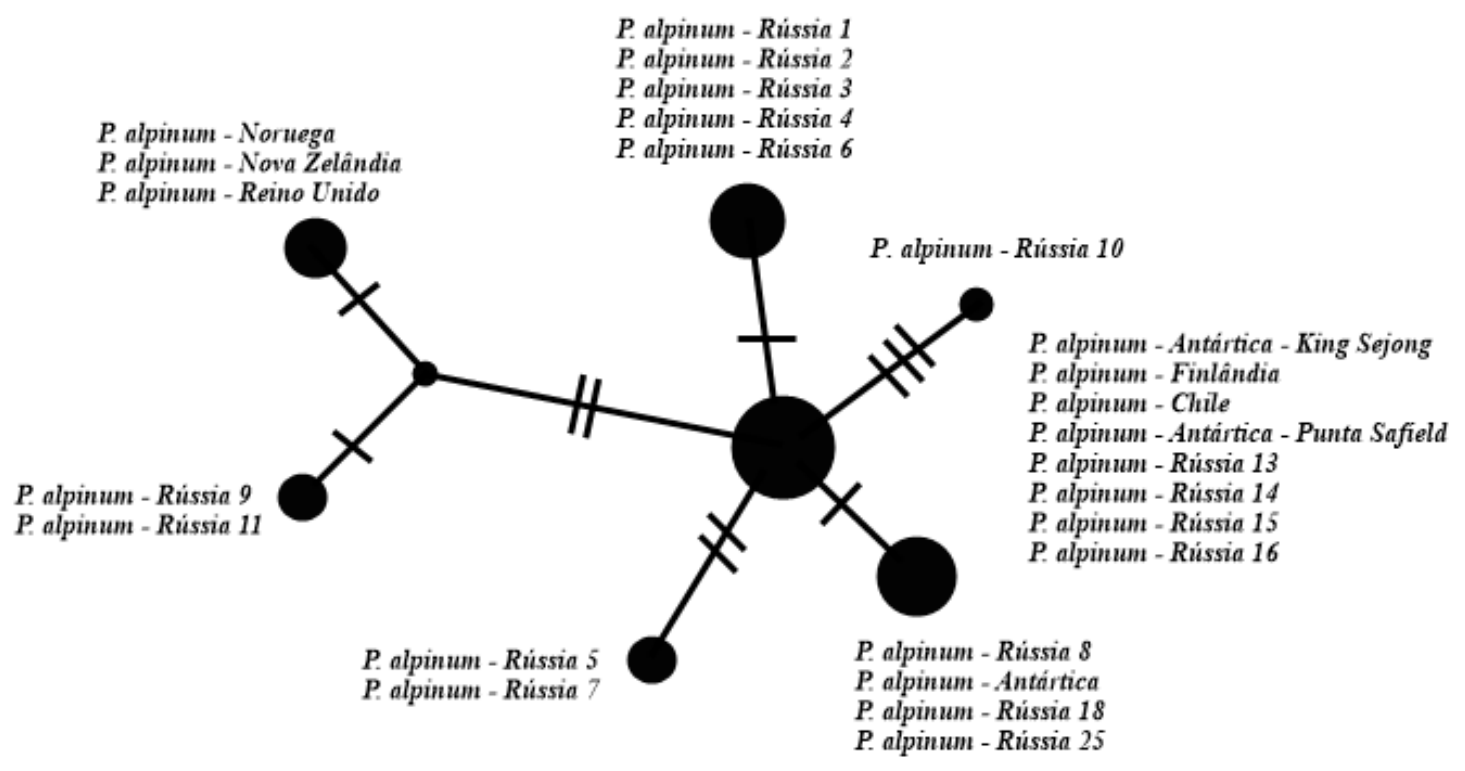

Figura 3. Representação da diversidade haplotípica de Polytrichastrum alpinum através de análise com marcador trnL-F. Fonte: Mundim, J. V.

Divergência Intraespecífica - Na análise de divergência intraespecífica (anexo VI) as amostras de Polytrichastrum alpinum oriundas da Rússia- $\mathrm{n}^{\circ} 7$ e 21, quando comparadas entre si apresentaram os maiores valores de divergência observados.

Entre as amostras do hemisfério sul não foi observada divergência $(0,00-0,00217)$ tão alta quanto aquela apresentada entre os indivíduos provenientes da Rússia $(0,01085)$. Na maioria dos exemplares da antártica e Chile não se observa variação.

Ainda ao se comparar amostras da antártica com exemplares da Noruega, alguns da Rússia, Nova Zelândia, Reino Unido, Finlândia e Chile, a divergência intraespecífica apresentada está numa faixa de zero a 0,00217.

Em estudo de diversidade intraespecífico realizado espécies de musgo do gênero Pohlia Hedw., as variações de diversidade intraespecífica obtidas variaram de 0,03 -0,38 para P. Pohlia andalusica (Höhn.) Broth. e 0,00 - 0,47 para Pohlia bolanderi (Lesq.) Broth., sendo a primeira consideração uma variação baixa e a segunda elevada para populações de uma mesma espécie, não sendo porém parâmetro de diferenciação de espécies, mas sim uma taxa 
de mutação elevada, resultado da influência antrópica no ambiente.Comparando-se os valores de diversidade obtidos em indivíduos de P. alpinum aos apresentados por Werner et al. (2005) para Pohlia, a variação obtida entre as populações de $P$. alpinum, 0,00 -0,01085, é inferior àquela considerada elevada dentro das populações de $P$. bolanderi, mostrando que mesmo em populações geograficamente distantes, $P$. alpinum possui baixa variedade intraespecífica.

Os valores obtidos na análise de diversidade intraespecífica mostram-se pouca ou nenhuma variação, mostrando não haver segregação entre as amostras oriundas de diferentes regiões e reafirmando que $P$. alpinum efetivamente é uma espécie bipolar.

\section{Considerações Finais}

A análise filogenética mostra que Polytrichastrum alpinum var. septentrionale não está no mesmo clado que $P$. alpinum e não apresenta a mutação que $P$. alpinum apresenta, sendo talvez uma indicação de que não se trate de uma variedade, mas provavelmente uma espécie distinta.

A análise de diversidade haplotípica aponta a existência de diferentes haplótipos de P. alpinum, mesmo dentre os espécimes da Antártica, podendo ter havido colonizações da espécie nesta localidade em diferentes momentos, podendo futuramente serem testadas hipóteses filogeográficas como realizado por Pisa et al. (2014).

As três análises aqui apresentadas corroboram com a classificação de bipolaridade proposta por Ochyra et al. (2008), para Polytrichastrum alpinum. 


\section{Referências Bibliográficas}

Bell, N. E. \& Hyvönen, J. 2010a. Phylogeny of the moss class Polytrichopsida (BRYOPHYTA): Generic-level structure and incongruent gene trees. Molecular Phylogenetics and Evolution. Disponível em: <www.elsevier.com/locate/ympev>.

. 2010b. A phylogenetic circumscription of Polytrichastrum (Polytrichaceae): Reassessment of sporophyte morphology supports molecular phylogeny. American Journal of Botany 97 (4): 566-7.

Brasil. 2014. Marinha do Brasil. s.d.. Comissão Interministerial para os Recursos do Mar. Proantar. Disponível em: <https://www.mar.mil.br/secirm/proantar.html〉.

Câmara, P. E. A. S. 2010. Métodos de extração de DNA de Bryophyta para analises filogenéticas. Boletim do Instituto de Botânica. 18:159-162.

Darriba D, Taboada G. L, Doallo R, \& Posada D. 2012. jModelTest 2: more models, new heuristics and parallel computing. Nature Methods 9(8), 772.

Doyle, J. J. \& J. L. Doyle. 1987. A rapid DNA isolation procedure for small quantities of fresh leaf tissue. Phytochemical Bulletin 19: 11-15.

Felsenstein, J. 1985. Confidence limits on phylogenies: an approach using the bootstrap. Evolution 39: 779-783.

Flora of North America Editorial Committee. 2007. Flora of North America. Bryophytes: Mosses, part 1. New York, Oxford University Press.

Hedenäs, L. 2012. Global phylogeography in Sanionia uncinata (Amblystegiaceae: Bryophyta). Botanical Journal of the Linnean Society 168: 19-42.

Higgins, D. G. \& P. M. Sharp. 1988. Clustal: A package for performing multiple sequence alignment on a micocomputer. Gene 73: 237-244. 
Ivanova, E; Neil, E. B.; Kuznetsova, O. I., Lee, H.; Park, P. \& Michael, S.. 2014. The Genus Polytrichastrum (Polytrichaceae) in Russia. Arctoa (2014) 23: 164-184.

Januario, B. B.; Cicarelli, R.M.B. \& Silva, M. T. A.. 2014. Aplicação De Códigos De Barras de Dna (Dna Barcoding) Na Identificação das Espécies de Senna Mill. (Fabaceae) E Casearia Jacq. (Salicaceae) Para Estudos De Variabilidade Genética. Universidade Estadual Paulista Júlio de Mesquita Filho.

Lang, A., Naciri, R. 2009. New chloroplast primers for intraspecific variation in Dicranum scoparium Hedw. (Dicranaceae) and amplification success in other bryophyte species. Molecular Ecology Resources 10, 735-737.

Kearse, M., Moir, R., Wilson, A., Stones-Havas, S., Cheung, M., Sturrock, S., Buxton, S., Cooper, A., Markowitz, S., Duran, C., Thierer, T., Ashton, B., Mentjies, P., \& Drummond, A. 2012. Geneious Basic: an integrated and extendable desktop software platform for the organization and analysis of sequence data.Bioinformatics, 28(12), 1647-1649.

Kato, K.; Arikawa, T.; Imura, S. \& Kanda, H.. 2013. Molecular identification and phylogeny of an aquatic moss species in Antarctic lakes. Polar Biol (2013) 36:1557-1568.

Longton, R. E., Holdgate, M. W.. 1979. The South Sandwich Islands: 4. Botany. Brit. Antarct. Surv. Sci.. Cambridge University Press.

Mullis, K. B. \& Faloona, F. A. 1987. Specific synthesis of DNA in vitro via a polymerasecatalyzed chain reaction. Methods Enzymol. 155: 335-350.

Müller K. 2005. SeqState - primer design and sequence statistics for phylogenetic DNA data sets. Applied Bioinformatics 4:65-69.

Müller, K., Quandt, D., Müller, J. \& Neinhuis, C. 2006. PhyDE®: Phylogenetic Data Editor. Disponível em: < www.phyde.de.>. 
Ochyra, R. 1998. The moss flora of King George Island, Antarctica. Cracow: Polish Academy of Sciences, W. Szafer Institute of Botany.

R., Lewis Smith, R.I. \& Bednarek-Ochyra H. 2008.The illustrated moss flora of Antarctica. Cambridge: Cambridge University Press.

Øvstedal, D.O. \& Lewis Smith, R.I. 2001. Lichens of Antarcticaand South Georgia: A guide to their Identification and Ecology. Cambridge: Cambridge University Press. $411 \mathrm{p}$.

Pisa, S.; Biersma, E. M.; Convey, P.; Patiño, J. , Vanderpoorten, A; Werner, O \& Ros. R. M.. 2014. The cosmopolitan moss Bryum argenteum in Antarctica: recent colonisation or in situ survival? Polar Biology.

PopArt. Disponível em: <http://popart.otago.ac.nz>.

Putzke, J. \& Pereira, A.B. 2001. The Antarctic mosses, with special reference to the South Shetland Islands. ULBRA (Universidade Luterana do Brasil), Canoas/RS. 196 pp.

Rambaut, A.. 2009. FigTree, ver.1.3.1. Disponível em: < www.tree.bio.ed.ac.uk/softwarefigtree.>.

Rambaut, A. \& Drummond, R. A. 2013. Tracer v1.5. Disponível em: $<$ http://beast.bio.ed.ac.uk/Tracer.>.

Ronquist, F. \& Huelsenbeck, J. P. 2003. MRBAYES 3: Bayesian phylogenetic.

Rozas, J., Librado, P., Sánchez -DelBarrio, J. C. \& Messeguer, Rozas, R.. 2010. DNAsp Software Version: 5.10.1. Disponível em: <http://www.ub.edu/dnasp/>.

Spagnuolo, V, Muscariello. L., Terracciano, S. \& Giordano, S.. 2007. Molecular biodiversity in the moss Leptodon smithii (Neckeraceae) in relation to habitat disturbance and fragmentation. J Plant Res 120:595-604. 
Spagnuolo, V., Terracciano, S. \& Giordano, S.. 2009. Trace element content and molecular biodiversity in the epiphytic moss Leptodon smithii: Two independent tracers of human disturbance. Chemosphere 74: 1158-1164.

Spielmann, A.A. \& Pereira, A.B. 2012. Lichens on the Maritime Antarctica (a small field guide to some common species).Glalia 4 (3): 01-28.

Stamatakis, A. 2014. "RAxML Version 8: A tool for Phylogenetic Analysis and PostAnalysis of Large Phylogenies”. In Bioinformatics.

Stech, M. \& Wagner D. 2005. Molecular relationships, biogeography, and evolution of Gondwanan Campylopus species (Dicranaceae, Bryopsida). Taxon 54: 377-382.

M., Sim-Sim, M., Kruijer \& J.D. 2010. Campylopus Brid. (Leucobryaceae) in Macaronesia revisited. Trop. Bryol. 31: 154-163.

M., Veldman, S., Larraín, J., Muñoz, J., Quandt, D., Hassel, K. \& Kruijer, J.D. 2013. Molecular species delimitation in the Racomitrium canescens complex (Grimmiaceae) and implications for DNA barcoding of species complexes in mosses. PLoS ONE 8(1): e53134. doi:10.1371/journal.pone.0053134.

Swofford, D. L. 2002. PAUP*. Phylogenetic analysis using parsimony (*and other methods). Version 4.: Sinauer Associates, Sunderland.

Taberlet, P., Gielly, L., Pautou, G. \& Bouvet, J.. 1991. Universal primers for amplification of three non-coding regions of chloroplast DNA. Plant Molecular Biology 17: 11051109.

Weitz, S. \& Heyn, C. C.. 1981. Intra-specific Differentiation Within the Cosmopolitan Moss Species Funaria hygrometrica Hedw.. The Bryologist 84(3), 1981, pp. 315-334.

Werner, O.; Rams, S \& Ros, R.M.. 2005. Genetic diversity of Pohlia bolanderi (Mniaceae), a 
rare and threatened moss in Sierra Nevada (Spain), estimated by ISSR molecular markers. Nova Hedwigia $813-4413$-419. 


\title{
ANEXOS
}

\begin{abstract}
Anexo I
Material examinado - Polytrichastrum alpinum
\end{abstract}

ALASCA. Sirius Point, Kiska Island, Aleutian Islands. Talbot, S. S. KISIA-X-17 (MO). Amilia Island, Aleutian Islands. Talbot, S. S. AML001-x-20 (MO). Adak Island. Schofield 125363 (DUKE). Attu Island. Loran C Base, Iawn. Schofield, W.B. 120224 (S).

ANTÁRTICA. Keller Penninsula. King George Islands. Punta Plaza. Câmara, P.E.A.S. 3317.UB (UB). King George Islands. Punta Hennz.Carvalho, A.M. 32 (UB). Ilha Penguin.Carvalho, A.M. 48 (UB). Deception.Carvalho, A.M. 62 (UB).Waley Bay. Carvalho, A.M. 72 (UB).Ilha Robert. Punta Prates. Carvalho, A.M. 80 (UB).Punta Hennequin. Bordin, J. 2391 (UB).Ilha Robert, Baía Eduard, Punta Prat. Bordin, J. 2563 (UB).Ilha Greenwich.. Bordin, J. 2607 (UB).Ilha Rei George. Ponta Turret. Aquino, P.P.U. 121 (UB).King George. King Sejong Station. Dantas, T.S. 152 (UB).King George. King George. Around King Sejong Station and ASPA 171. Dantas, T.S. 153 (UB).Ilha Rei Jorge. Península Fildes. Mundim, J.V.310 (UB).Ilha Rei Jorge. Península Fildes. Em frente Platô Flat. Mundim, J.V.437 (UB).Almiranty Bay. Arctowski Station. ASPA 128. Mundim, J.V.57 (UB).Almiranty Bay. Arctowski Station. Thomas Point. Mundim, J.V.123 (UB).. South Shetland Islands. Ardley. Oliveira H.C 2462 (UB). South Shetland Islands. Ilha Elefante, arredores do abrigo Emílio Goeldi. Costa, D.P.6275 (RB/UB). Península Bayers, Livinston Island. Convey, P. 766 (AAS). Alexander Bayers. Convey, P. 849 (AAS). South Georgia, Cape Rosa. Osborne, J. 294 (AAS). Signy Island, Changing lake. Smith, R.I.L. 10770 A (AAS) . Candlemas Island. Convey, P. 193 A (AAS). Sarcophagus Point. Convey, P. 167 B (AAS). South Orkney Island. Smith, R.I.L. 8688 (AAS). Collins Point, Deception Island. Smith, R.I.L. 3620 C (AAS). Kerguelen. Bell, B. G. 3124 (AAS). South Georgia, Block Lake. Smith, R.I.L. 100367 (AAS).

CHILE. Prov. Nuble. Termas de Chillán. Ireland, R. R.; Bellolio, G. 31139 (MO). Ilha Navarino. Puerto Willians. Câmara, P.E.A.S. 702.

CHINA. Yunnan Province, Gaoligongshan Region. Shevock, J. R. 26796 (MO). 
CANADÁ. Ontário, Espanola. Ireland, R.R. 22332 (S). New Brunswick. Restigouche C.O. South Branch Benjamin River. Bagnell, B. A. 599 (NBM/ S). Britsh Columbia. Squamish Lillooet Distr . Buck, W. R. 54765 (MO). Québec, bic. Faubert, H. J. 6129 (MO).

EUA. Minnesota, Cook Country. Allen, B. 9749 (S/MO). Maine, Tow of durham. Allen, B. 27848 (MO). Michigan. Keweenaw Co. Smith, E. M. 921 (MO).

ISLÂNDIA. Egilsson 43089 (ICEL).

JAPÃO. Honshu, Nagano-Ken, Mt. Ontake. Iwatsuki, Z. s/n (S).

SIBÉRIA. Republic Sakha (Yakutia), Ust- Maya Distr. Ivanova, E. I. s/n (SASY/ NSK/ S). 


\begin{abstract}
ANEXO II
Voucher das mostras observadas sob microscopia eletrônica de varredura
\end{abstract}

\begin{tabular}{|c|c|c|c|c|}
\hline Localidade & Coletor & $\mathbf{N}^{0}$ de coleta & Ano & Herbário \\
\hline $\begin{array}{l}\text { Alasca - } \\
\text { Aleutian } \\
\text { Islands. }\end{array}$ & Talbot & KIS1A-X-17 & 2002 & $\mathrm{MO}$ \\
\hline $\begin{array}{l}\text { Alasca- Adak } \\
\text { Island. }\end{array}$ & Shoefild & 125363 & - & DUKE \\
\hline Antártica & Mundim, J. V. & 535 & 2015 & UB \\
\hline Antártica & Mundim, J. V. & 372 & 2015 & UB \\
\hline Antártica & Victoria, F. & 45 & 2003 & $\mathrm{RB}$ \\
\hline Antártica & Bordin, J. & 2564 & - & $\mathrm{SP}$ \\
\hline Antártica & Aquino, $\mathrm{P}$ & 143 & 2014 & UB \\
\hline Chile & $\begin{array}{l}\text { Ireland \& } \\
\text { Bellolio }\end{array}$ & & 2002 & MO \\
\hline $\begin{array}{l}\text { Canadá. Britsh } \\
\text { Columbia. }\end{array}$ & Buck & 54765 & - & $\mathrm{NY}$ \\
\hline EUA - Maine & Allen. B. & 27848 & 2006 & MO \\
\hline $\begin{array}{c}\text { Sibéria (região } \\
\text { leste) }\end{array}$ & Ivanova, E. I & s.n & 2000 & SASY/NSK/S \\
\hline Islândia & Egilsson & 43089 & - & ICEL \\
\hline
\end{tabular}


ANEXO III

Voucher das mostras observadas em estudo anatômico

\begin{tabular}{|c|c|c|c|c|}
\hline Localidade & Coletor & \multicolumn{1}{|c|}{$\mathbf{N}^{\mathbf{0}}$ de coleta } & Ano & Herbário \\
\hline $\begin{array}{c}\text { Alasca - } \\
\text { Aleutian } \\
\text { Islands. }\end{array}$ & Talbot & KIS1A-X-17 & 2002 & MO \\
\hline $\begin{array}{c}\text { China. Sichuan } \\
\text { Province. } \\
\text { Jichou range, } \\
\text { Hengduan } \\
\text { Montains. }\end{array}$ & Shevock, J. R. & 36045 & 2010 & MO \\
\hline Antártica & Mundim, J. V. & 535 & 2015 & UB \\
\hline Antártica & Mundim, J. V. & 372 & 2015 & UB \\
\hline
\end{tabular}




\section{ANEXO IV}

Voucher das amostras do GenBank utilizadas nas análises moleculares.

\begin{tabular}{|c|c|c|}
\hline Voucher Genbank & Espécie & Localidade \\
\hline AF545011 & Meiotrichum lyallii (Mitt.) G.L. Merr. & - \\
\hline KM381983 & Polytrichastrum altaicum Ignatov \& G.L. Merr. & Rússia \\
\hline KM381984 & Polytrichastrum altaicum Ignatov \& G.L. Merr. & Rússia \\
\hline KM381982 & Polytrichastrum altaicum Ignatov \& G.L. Merr. & Rússia \\
\hline KM381981 & Polytrichastrum altaicum Ignatov \& G.L. Merr. & Rússia \\
\hline GU569734 & Polytrichastrum altaicum Ignatov \& G.L. Merr. & Rússia \\
\hline KM361636 & Polytrichastrum alpinum (Hedw.) G.L. Sm. & Antártica \\
\hline GU569729 & Polytrichastrum alpinum (Hedw.) G.L. Sm. & Reino Unido \\
\hline GU569732 & Polytrichastrum alpinum (Hedw.) G.L. Sm. & Noruega \\
\hline GU569731 & Polytrichastrum alpinum (Hedw.) G.L. Sm. & Nova Zelândia \\
\hline GU569730 & Polytrichastrum alpinum (Hedw.) G.L. Sm. & Chile \\
\hline GU569733 & Polytrichastrum alpinum (Hedw.) G.L. Sm. & Finlândia \\
\hline KM381980 & Polytrichastrum alpinum (Hedw.) G.L. Sm. & $\begin{array}{l}\text { Estados } \\
\text { Unidos }\end{array}$ \\
\hline AF545031 & Polytrichastrum alpinum (Hedw.) G.L. Sm. & - \\
\hline KM381963 & Polytrichastrum alpinum (Hedw.) G.L. Sm. & Rússia \\
\hline KM381971 & Polytrichastrum alpinum (Hedw.) G.L. Sm. & Rússia \\
\hline KM381969 & Polytrichastrum alpinum (Hedw.) G.L. Sm. & Rússia \\
\hline KM381978 & Polytrichastrum alpinum (Hedw.) G.L. Sm. & Rússia \\
\hline KM381965 & Polytrichastrum alpinum (Hedw.) G.L. Sm. & Rússia \\
\hline KM381977 & Polytrichastrum alpinum (Hedw.) G.L. Sm. & Rússia \\
\hline KM381975 & Polytrichastrum alpinum (Hedw.) G.L. Sm. & Rússia \\
\hline KM381966 & Polytrichastrum alpinum (Hedw.) G.L. Sm. & Rússia \\
\hline KM381962 & Polytrichastrum alpinum (Hedw.) G.L. Sm. & Rússia \\
\hline KM381959 & Polytrichastrum alpinum (Hedw.) G.L. Sm. & Rússia \\
\hline KM381979 & Polytrichastrum alpinum (Hedw.) G.L. Sm. & Rússia \\
\hline KM381964 & Polytrichastrum alpinum (Hedw.) G.L. Sm. & Rússia \\
\hline KM381970 & Polytrichastrum alpinum (Hedw.) G.L. Sm. & Rússia \\
\hline KM381976 & Polytrichastrum alpinum (Hedw.) G.L. Sm. & Rússia \\
\hline KM381972 & Polytrichastrum alpinum (Hedw.) G.L. Sm. & Rússia \\
\hline KM381968 & Polytrichastrum alpinum (Hedw.) G.L. Sm. & Rússia \\
\hline KM381974 & Polytrichastrum alpinum (Hedw.) G.L. Sm. & Rússia \\
\hline KM381973 & Polytrichastrum alpinum (Hedw.) G.L. Sm. & Rússia \\
\hline KM381959 & Polytrichastrum alpinum (Hedw.) G.L. Sm. & Rússia \\
\hline KM381960 & Polytrichastrum alpinum (Hedw.) G.L. Sm. & Rússia \\
\hline KM381961 & Polytrichastrum alpinum (Hedw.) G.L. Sm. & Rússia \\
\hline KM381989 & Polytrichastrum alpinum var. septentrionale (Brid.) G.L. Sm. & Rússia \\
\hline KM381990 & Polytrichastrum alpinum var. septentrionale (Brid.) G.L. Sm. & Rússia \\
\hline KM381991 & Polytrichastrum alpinum var. septentrionale (Brid.) G.L. Sm. & Rússia \\
\hline KM381988 & Polytrichastrum alpinum var. septentrionale (Brid.) G.L. Sm. & Rússia \\
\hline GU569736 & Polytrichastrum emodi G.L. Sm. & Butão \\
\hline GU569741 & Polytrichastrum norwegicum (Hedw.) Schljakov & Canadá \\
\hline GU569740 & Polytrichastrum norwegicum (Hedw.) Schljakov & Finlândia \\
\hline GU569739 & Polytrichastrum norwegicum (Hedw.) Schljakov & Finlândia \\
\hline GU569744 & Polytrichastrum papillatum G.L. Sm. & Butão \\
\hline KM381987 & Polytrichastrum papillatum G.L. Sm. & Rússia \\
\hline KM381994 & Polytrichastrum sexangulare (Flörke ex Brid.) G.L. Sm. & Rússia \\
\hline KM381993 & Polytrichastrum sexangulare (Flörke ex Brid.) G.L. Sm. & Rússia \\
\hline
\end{tabular}




\begin{tabular}{|c|c|c|}
\hline GU569746 & Polytrichastrum sexangulare (Flörke ex Brid.) G.L. Sm. & Canadá \\
\hline GU569745 & Polytrichastrum sexangulare (Flörke ex Brid.) G.L. Sm. & Finlândia \\
\hline KM381995 & Polytrichastrum sphaerothecium (Besch.) J.-P. Frahm & Rússia \\
\hline GU569749 & Polytrichastrum sphaerothecium (Besch.) J.-P. Frahm & Islândia \\
\hline GU569748 & Polytrichastrum sphaerothecium (Besch.) J.-P. Frahm & Japão \\
\hline GU569747 & Polytrichastrum sphaerothecium (Besch.) J.-P. Frahm & Rússia \\
\hline GU569750 & Polytrichastrum tenellum (Müll. Hal.) G.L. Sm. & Bolívia \\
\hline
\end{tabular}

Obs: O material sequenciado a partir das coletas realizadas na Antártica ainda não está disponível para visualização no GenBank. 


\begin{abstract}
ANEXO V
Descrições das sequências de marcador trnL-F, das análises moleculares. CI: Índice de consistência e CR: índice de retenção.
\end{abstract}

\begin{tabular}{ll}
\hline Caracteristicas & Região trnL-F \\
\hline Taxons incluídos & 56 \\
Comprimento da Matriz & 485 \\
Caracteres variáveis & 10 \\
Caracteres Informativos na MP & 19 \\
$\mathrm{~N}^{\circ}$ de Árvores de MP & 10.000 \\
Árvores length & 73 \\
$\mathrm{CI}$ & 1 \\
$\mathrm{RI}$ & 1
\end{tabular}

Modelo de substituição

GRT 


\section{ANEXO VI}

Análise de Diversidade Intraespecífica entre espécimes de Polytrichastrum alpinum

\begin{tabular}{|c|c|c|c|c|c|c|c|c|c|c|c|c|c|c|c|c|c|}
\hline & 1 & 2 & 3 & 4 & 5 & 6 & 7 & 8 & 9 & 10 & 11 & 12 & 13 & 14 & 15 & 16 & 17 \\
\hline P. alpinum - Antártica- King Sejong & - & & & & & & & & & & & & & & & & \\
\hline P. alpinum - Antártica- Punta Safield & 0,00000 & - & & & & & & & & & & & & & & & \\
\hline P. alpinum - Antártica & 0,00217 & 0,00217 & - & & & & & & & & & & & & & & \\
\hline P. alpinum - Chile & 0,00000 & 0,00000 & 0,00217 & - & & & & & & & & & & & & & \\
\hline P. alpinum -Rússia 10 & 0,00000 & 0,00000 & 0,00216 & 0,00000 & - & & & & & & & & & & & & \\
\hline P. alpinum - Rússia 12 & 0,00000 & 0,00000 & 0,00217 & 0,00000 & 0,00000 & - & & & & & & & & & & & \\
\hline P. alpinum - Rússia 2 & 0,00217 & 0,00217 & 0,00434 & 0,00217 & 0,00224 & 0,00217 & - & & & & & & & & & & \\
\hline P. alpinum - Noruega & 0,00000 & 0,00000 & 0,00217 & 0,00000 & 0,00000 & 0,00000 & 0,00217 & - & & & & & & & & & \\
\hline P. alpinum - N. Zelândia & 0,00000 & 0,00000 & 0,00217 & 0,00000 & 0,00000 & 0,00000 & 0,00217 & 0,00000 & - & & & & & & & & \\
\hline P. alpinum - Reino Unido & 0,00000 & 0,00000 & 0,00217 & 0,00000 & 0,00000 & 0,00000 & 0,00217 & 0,00000 & 0,00000 & - & & & & & & & \\
\hline P. alpinum - Finlândia & 0,00000 & 0,00000 & 0,00217 & 0,00000 & 0,00000 & 0,00000 & 0,00217 & 0,00000 & 0,00000 & 0,00000 & - & & & & & & \\
\hline P. alpinum - Rússia 8 & 0,00217 & 0,00217 & 0,00000 & 0,00217 & 0,00216 & 0,00217 & 0,00434 & 0,00217 & 0,00217 & 0,00217 & 0,00217 & - & & & & & \\
\hline P. alpinum - Rússia 5 & 0,00434 & 0,00434 & 0,00651 & 0,00434 & 0,00433 & 0,00434 & 0,00651 & 0,00451 & 0,00451 & 0,00451 & 0,00434 & 0,00651 & - & & & & \\
\hline P. alpinum - USA & 0,00251 & 0,00251 & 0,00503 & 0,00251 & 0,00259 & 0,00251 & 0,00000 & 0,00254 & 0,00254 & 0,00254 & 0,00251 & 0,00503 & 0,00502 & - & & & \\
\hline P. alpinum - Rússia 3 & 0,00217 & 0,00217 & 0,00434 & 0,00217 & 0,00224 & 0,00217 & 0,00000 & 0,00217 & 0,00217 & 0,00217 & 0,00217 & 0,00434 & 0,00651 & 0,00000 & - & & \\
\hline P. alpinum - Rússia 4 & 0,00217 & 0,00217 & 0,00434 & 0,00217 & 0,00224 & 0,00217 & 0,00000 & 0,00217 & 0,00217 & 0,00217 & 0,00217 & 0,00434 & 0,00651 & 0,00000 & 0,00000 & - & \\
\hline P. alpinum - Rússia 1 & 0,00217 & 0,00217 & 0,00434 & 0,00217 & 0,00224 & 0,00217 & 0,00000 & 0,00217 & 0,00217 & 0,00217 & 0,00217 & 0,00434 & 0,00651 & 0,00000 & 0,00000 & 0,00000 & 0000 \\
\hline P. alpinum - Rússia 6 & 0,00217 & 0,00217 & 0,00434 & 0,00217 & 0,00224 & 0,00217 & 0,00000 & 0,00217 & 0,00217 & 0,00217 & 0,00217 & 0,00434 & 0,00651 & 0,00000 & 0,00000 & 0,00000 & 0,00000 \\
\hline P. alpinum - Rússia 9 & 0,00000 & 0,00000 & 0,00217 & 0,00000 & 0,00000 & 0,00000 & 0,00217 & 0,00000 & 0,00000 & 0,00000 & 0,00000 & 0,00217 & 0,00451 & 0,00254 & 0,00217 & 0,00217 & 0,00217 \\
\hline P. alpinum - Rússia 11 & 0,00000 & 0,00000 & 0,00217 & 0,00000 & 0,00000 & 0,00000 & 0,00217 & 0,00000 & 0,00000 & 0,00000 & 0,00000 & 0,00217 & 0,00451 & 0,00254 & 0,00217 & 0,00217 & 0,00217 \\
\hline P. alpinum - Rússia 15 & 0,00000 & 0,00000 & 0,00217 & 0,00000 & 0,00000 & 0,00000 & 0,00217 & 0,00000 & 0,00000 & 0,00000 & 0,00000 & 0,00217 & 0,00434 & 0,00251 & 0,00217 & 0,00217 & 0,00217 \\
\hline P. alpinum - Rússia 16 & 0,00000 & 0,00000 & 0,00217 & 0,00000 & 0,00000 & 0,00000 & 0,00217 & 0,00000 & 0,00000 & 0,00000 & 0,00000 & 0,00217 & 0,00434 & 0,00251 & 0,00217 & 0,00217 & 0,00217 \\
\hline P. alpinum - Rússia 14 & 0,00000 & 0,00000 & 0,00217 & 0,00000 & 0,00000 & 0,00000 & 0,00217 & 0,00000 & 0,00000 & 0,00000 & 0,00000 & 0,00217 & 0,00434 & 0,00251 & 0,00217 & 0,00217 & 0,00217 \\
\hline P. alpinum - Rússia 13 & 0,00000 & 0,00000 & 0,00217 & 0,00000 & 0,00000 & 0,00000 & 0,00217 & 0,00000 & 0,00000 & 0,00000 & 0,00000 & 0,00217 & 0,00434 & 0,00251 & 0,00217 & 0,00217 & 0,00217 \\
\hline P. alpinum - Antártica & 0,00217 & 0,00217 & 0,00000 & 0,00217 & 0,00216 & 0,00217 & 0,00434 & 0,00217 & 0,00217 & 0,00217 & 0,00217 & 0,00000 & 0,00651 & 0,00503 & 0,00434 & 0,00434 & 0,00434 \\
\hline P. alpinum - Rússia 17 & 0,00000 & 0,00000 & 0,00000 & 0,00000 & 0,00000 & 0,00000 & 0,00228 & 0,00000 & 0,00000 & 0,00000 & 0,00000 & 0,00000 & 0,00464 & 0,00266 & 0,00228 & 0,00228 & 0,00228 \\
\hline P. alpinum - Rússia 18 & 0,00217 & 0,00217 & 0,00000 & 0,00217 & 0,00216 & 0,00217 & 0,00434 & 0,00217 & 0,00217 & 0,00217 & 0,00217 & 0,00000 & 0,00651 & 0,00503 & 0,00434 & 0,00434 & 0,00434 \\
\hline P. alpinum - Rússia 19 & 0,00000 & 0,00000 & 0,00000 & 0,00000 & 0,00000 & 0,00000 & 0,00217 & 0,00000 & 0,00000 & 0,00000 & 0,00000 & 0,00000 & 0,00441 & 0,00252 & 0,00217 & 0,00217 & 0,00217 \\
\hline P. alpinum - Rússia 20 & 0,00000 & 0,00000 & 0,00000 & 0,00000 & 0,00000 & 0,00000 & 0,00257 & 0,00000 & 0,00000 & 0,00000 & 0,00000 & 0,00000 & 0,00260 & 0,00264 & 0,00257 & 0,00257 & 0,00257 \\
\hline P. alpinum - Rú & 0,00868 & 0,00868 & 0,00651 & 0,00868 & 0,00857 & 0,00868 & 0,01085 & 0,00892 & 0,00892 & 0,00892 & 0,00868 & 0,00651 & 0,01302 & 0,00503 & 0,01085 & 0,01085 & 0,01085 \\
\hline P. alpinum - Rússia 7 & 0,00434 & 0,00434 & 0,00651 & 0,00434 & 0,00433 & 0,00434 & 0,00651 & 0,00451 & 0,00451 & 0,00451 & 0,00434 & 0,00651 & 0,00000 & 0,00502 & 0,00651 & 0,00651 & 0,00651 \\
\hline
\end{tabular}




\section{Continuação Anexo VII}

$\begin{array}{ll}\text { P. alpinum - Rússia } 9 & 0,00217 \\ \text { P. alpinum - Rússia } 11 & 0,00217 \\ \text { P. alpinum - Rússia } 15 & 0,00217 \\ \text { P. alpinum - Rússia } 16 & 0,00217 \\ \text { P. alpinum - Rússia } 14 & 0,00217 \\ \text { P. alpinum - Rússia } 13 & 0,00217 \\ \text { P. alpinum - Antártica } & 0,00434 \\ \text { P. alpinum - Rússia } 17 & 0,00228 \\ \text { P. alpinum - Rússia } 18 & 0,00434 \\ \text { P. alpinum - Rússia } 19 & 0,00217 \\ \text { P. alpinum - Rússia 20 } & 0,00257 \\ \text { P. alpinum - Rússia } 21 & 0,01085 \\ \text { P. alpinum - Rússia } 7 & 0,00651\end{array}$

$0,00000-$

$0,00000 \quad 0,00000$

$\begin{array}{llll}0,00000 & 0,00000 & 0,00000 & -\end{array}$

$\begin{array}{llll}0,00000 & 0,00000 & 0,00000 & 0,00000\end{array}$

$\begin{array}{lllll}0,00000 & 0,00000 & 0,00000 & 0,00000 & 0,00000\end{array}$

$\begin{array}{llllll}0,00217 & 0,00217 & 0,00217 & 0,00217 & 0,00217 & 0,00217\end{array}$

$\begin{array}{llllllll}0,00000 & 0,00000 & 0,00000 & 0,00000 & 0,00000 & 0,00000 & 0,00000 & -\end{array}$

$\begin{array}{llllllll}0,00217 & 0,00217 & 0,00217 & 0,00217 & 0,00217 & 0,00217 & 0,00000 & 0,00000\end{array}$

$\begin{array}{lllllllll}0,00000 & 0,00000 & 0,00000 & 0,00000 & 0,00000 & 0,00000 & 0,00000 & 0,00000 & 0,00000\end{array}$

$\begin{array}{llllllllll}0,00000 & 0,00000 & 0,00000 & 0,00000 & 0,00000 & 0,00000 & 0,00000 & 0,00000 & 0,00000 & 0,00000 \\ -\end{array}$

$\begin{array}{lllllllllll}0,00892 & 0,00892 & 0,00868 & 0,00868 & 0,00868 & 0,00868 & 0,00651 & 0,00689 & 0,00651 & 0,00660 & 0,00000\end{array}$

$\begin{array}{llllllllllllll}0,00451 & 0,00451 & 0,00434 & 0,00434 & 0,00434 & 0,00434 & 0,00651 & 0,00464 & 0,00651 & 0,00441 & 0,00260 & 0,01302 & -\end{array}$ 
